\title{
LEPTOSPIRA AND LEPTOSPIROSIS
}

\section{Cyrille Goarant}

Institut Pasteur International Network

Noumea, New Caledonia

\section{Gabriel Trueba}

Universidad San Francisco De Quito, Institute of Microbiology

Quito, Ecuador

\section{Emilie Bierque}

Institut Pasteur International Network

Noumea, New Caledonia

\section{Roman Thibeaux}

Institut Pasteur International Network

Noumea, New Caledonia

\section{Benjamin Davis}

Virginia Tech

Blacksburg, United States

Alejandro de la Pena-Moctezuma

Universidad Nacional Autonoma de Mexico

Gustavo A. Madero, Mexico 


\section{Copyright:}

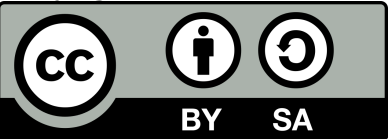

This publication is available in Open Access under the Attribution-ShareAlike 3.0 IGO (CC-BY-SA 3.0 IGO) license (http://creativecommons.org/licenses/by-sa/3.0/igo). By using the content of this publication, the users accept to be bound by the terms of use of the UNESCO Open Access Repository (http://www.unesco.org/openaccess/terms-use-ccbysa-en).

\section{Disclaimer:}

The designations employed and the presentation of material throughout this publication do not imply the expression of any opinion whatsoever on the part of UNESCO concerning the legal status of any country, territory, city or area or of its authorities, or concerning the delimitation of its frontiers or boundaries. The ideas and opinions expressed in this publication are those of the authors; they are not necessarily those of UNESCO and do not commit the Organization.

\section{Citation:}

Goarant, C., Trueba, G., Bierque, E., Thibeaux, R., Davis, B. and De la Peña Moctezuma. (2019). Leptospira and Leptospirosis. In: J.B. Rose and B. Jiménez-Cisneros, (eds) Water and Sanitation for the 21st Century: Health and Microbiological Aspects of Excreta and Wastewater Management (Global Water Pathogen Project). ( A. Pruden, N. Ashbolt and J. Miller (eds), Part 3: Specific Excreted Pathogens: Environmental and Epidemiology Aspects - Section 2: Bacteria), Michigan State University, E. Lansing, MI, UNESCO. https://doi.org/10.14321/waterpathogens.26

Acknowledgements: K.R.L. Young, Project Design editor; Website Design: Agroknow (http://www.agroknow.com)

Last published: May 30, 2019 


\section{Summary}

Leptospirosis is an important and often ignored disease affecting more than one million people a year worldwide, from which 50,000 die. No serovar is known to be adapted to humans, so humans acquire the disease directly from animals (contact with urine or tissues) or indirectly (contact with urine contaminated water). The three main environments showing transmission risks are water-based, rodent-borne and livestock/pet-borne environments. Leptospirosis occurs worldwide but it is more frequently found in humid tropical climates, especially in regions with poor sanitary infrastructure, deficient drainage, and as a result large numbers of rats. The contact with natural bodies of water (wet farming) increases the risk of infection. Outbreaks tend to occur during rainy seasons and it has been associated with flooding. The disease has a broad geographical distribution due to the large spectrum of hosts including domestic and wild mammals. Leptospirosis affects risk groups that are exposed to animal reservoirs or urine contaminated environments and people in contact with natural bodies of water. Leptospirosis is regarded as the most widespread zoonosis.

Leptospirosis is caused by spirochetes of the genus Leptospira which comprises 20 species that are phylogenetically separated into 3 clusters: 9 pathogenic, 6 saprophytic, and 5 intermediate. The etiologic agents of this disease are pathogenic and intermediate species of Leptospira which comprise more than 260 serovars. Pathogenic and intermediate clusters have been reported to cause infection and in this text we will refer to them as parasitic Leptospira. The organism is a thin spirochete of 0.1 to $0.2 \mu \mathrm{m}$ in diameter and 6 to $12 \mu \mathrm{m}$ in length, so that it can be filtered through $0.45 \mu \mathrm{m}$ filters. It is very motile showing translational motility, travelling approximately 20 $\mu \mathrm{m}$ in 2 to 3 seconds in ordinary media.

Leptospirosis is considered a neglected disease, and the spirochete causing this disease, Leptospira is difficult to recover in culture and only recently molecular genetics tools have been developed suitable for the study of this spirochete. These factors have contributed to a lag in the understanding of its virulence mechanisms, its immunogenic properties and finally a lag in the development of vaccines that may induce strong and durable protection.

To date, different methods for inactivation of leptospires for use as vaccines have been applied, these include formalin, phenol, ethanol, heat, freeze and thaw and radiation; and after 100 years the only licensed vaccines are whole leptospira inactivated bacterins. These have been used to immunize animals, mainly dogs, cattle and pigs. because of problems with components of the culture media and reactogenicity, such bacterins have not been widely accepted for use in humans, however human bacterin vaccines have been used successfully in several regions, including China, Japan, Cuba, and Europe. No live vaccines are currently licensed. very limited mainly because it is difficult to isolate these spirochetes from surface waters or soil without getting contamination with saprophytic Leptospira. However, genomic studies suggest that parasitic Leptospira evolved from an environmental (free living) Leptospira found in water or mud, similarly to the contemporary members of the saprophytic cluster (such as L. biflexa). There seems to be some evolutionary variation within parasitic leptospires; some species (such as L. interrogans) have retained genes associated to environmental survival whereas other parasitic leptospires (such as L. borgpetersenii) seem to have lost these genes. Leptospiral survival in water is bolstered by viscous material such as agar (and possibly biofilm). Some strains of parasitic Leptospira are able to produce biofilms when incubated in fresh water even under the absence of nutrients, furthermore L. interrogans (Pathogenic cluster) has been found in nature associated to biofilms formed by environmental bacteria. Some parasitic leptospira are able to produce biofilm when incubated in distilled water (low nutrient conditions) and seemed to detect nutrients such as fatty acids causing the dispersion (release) of leptospiral cells from the biofilm. It has been observed that leptospiral biofilm has a five to sixfold increase in antibiotic resistance in all the strains used. It is tempting to speculate that biofilms may protect pathogenic Leptospira against other toxic compounds in the environment. The role of biofilm in the transmission of Leptospira to susceptible hosts are still unclear.

Soil may also play a role in environmental survival; some researchers have shown that Leptospira survived in the wet soil on dry days and appeared in the surface water on rainy days, suggesting that soil could be a reservoir for leptospires in the environment. Even though leptospires are considered as fragile spirochetes, studies have shown that they can survive and even maintain their virulence despite unfavorable conditions such as cold and nutrient-poor acidic waters after up to 20 months.

There is no standard protocols to culture parasitic species of Leptospira from bodies of fresh water or soil. There are only few reports describing isolation of parasitic Leptospira from environmental samples and the reports show little success; the main difficulty in the isolation of these species is the overgrowth of environmental bacteria or the fast-growing saprophytic Leptospira. Molecular techniques are a lot more promising at detecting parasitic Leptospira in the environment. Many PCR protocols have been developed using mainly genes that are present only in pathogenic Leptospira such as the hemolysis-associated protein-1gene, lipL32, or pathogenic specific sequences of genes such as flaB, secY, and $16 \mathrm{~S}$ ribosomal gene. The main limitation of many of these analyses is that they fail to detect parasitic Leptospira of the intermediate cluster which are commonly found in water. Detection of genomic DNA sequences do not guaranty the viability of bacteria in water or other samples. RNA methods are under development to detect viable bacteria. 


\subsection{Epidemiology of the Disease and Pathogen(s)}

Leptospirosis is a deadly bacterial infection caused by pathogenic members of the genus Leptospira. Human leptospirosis has long been recognized as an environmental disease, with documented reports dating at least a century ago (Noguchi, 1918). Today, it is clearly acknowledged that most human infections originate from environmental exposure to water and soils contaminated by the urine excreted by infected animals. Human exposure to contaminated water mostly occurs through bathing or swimming in natural freshwater bodies, but isolated contamination of water supplies has also been involved in outbreaks of leptospirosis (reviewed in Levett, 2001).

Leptospirosis is very challenging to diagnose clinically. Educating clinicians about considering leptospirosis when patients present with acute febrile syndromes, particularly when there has been recent exposure to freshwater, could greatly improve diagnosis. Although leptospires are considered to be very fragile bacteria, being highly susceptible to a number of physical and chemical agents (Faine et al., 1999), they present an astonishing capacity to survive in freshwater ecosystems for weeks to months. However, little is known about the fate of pathogenic leptospires in water, despite the importance of such knowledge towards preventing this potentially fatal bacterial infection in humans.

There are three main reasons for limited knowledge about the fate of leptospires in water. First, the genus Leptospira comprises both virulent species, which are the etiological agents of human and animal leptospirosis, and saprophytic species, which are non-virulent normal inhabitants of freshwater ecosystems. Second, the taxonomy of the genus has long been based on serology, which distinguished almost 300 serovars grouped into more than 23 serogroups, but only two species (Leptospira interrogans sensu lato, which grouped all virulent species, and Leptospira biflexa sensu lato for all saprophytic species until the 1980s). The two previous species grouping of the 1980s have since been declared invalid, based on more recent characterization using genetic molecular taxonomy, which to date has discriminated at least 35 species (Brenner et al., 1999; Ramadass et al., 1992; Yasuda et al., 1987; Thibeaux et al., 2018b; Thibeaux et al., 2018a). In addition, another group of Leptospira (named "intermediates") has also been described (Schmid et al., 1986; Perolat et al., 1998), which currently incorporates 11 species with at least some displaying some degree of virulence. Early scientific reports did not always describe whether the leptospires studied had some virulence potential. The older literature therefore needs to be interpreted with caution to consider these taxonomical differences. Third, and finally, yet as importantly, pathogenic strains of Leptospira are slowgrowing, and can easily become overgrown by saprophytic species and other microorganisms, even with selective culture medium. Still, the body of literature published over the last century is proving useful in building some knowledge about the occurrence, persistence and survival of leptospires in water. Putting this knowledge together can help improve prevention of this significant, possibly reemerging, environmental disease.

\subsection{Global Burden of Disease}

\subsubsection{Global distribution}

One of the first descriptions of the disease now known as leptospirosis was reported by Larrey in 1812, during a blockade of Napoleon's troops in Cairo; and more than a century ago Adolph Weil described a severe form of the disease, since known as Weil's disease. Leptospirosis is an important and often ignored disease affecting more than one million people per year worldwide, with 58,900 deaths (Costa et al., 2015; Ko et al., 2009). Leptospirosis occurs worldwide, but it is more frequently found in humid tropical climates, especially in regions with poor sanitary infrastructure, deficient drainage, and as a result, large numbers of a key animal reservoir: rats. While inappropriate management of human excreta may support rodent densities and thereby be a contributing factor, human infections are often associated with exposures to natural bodies of water (wet farming). Outbreaks tend to occur during rainy seasons and it has been associated with flooding (Della Rossa et al., 2016; Ganoza et al., 2006; Trevejo et al., 1998; Concepcion-Acevedo et al., 2018; Reardon, 2017). The disease has a broad geographical distribution due to the large spectrum of hosts, including domestic and wild mammals, including rats and mice, which harbor the bacterium in their kidneys and release it through their urine (Carmona Gasca et al., 2013; Dietrich et al., 2015; Ko et al., 2009). Various animal hosts are further discussed in Section 1.3.2. Leptospirosis affects risk groups that are exposed to animal reservoirs or urinecontaminated environments, such as veterinarians, abattoir workers, sewage workers, military personnel, people in contact with natural bodies of water, and increasingly including individuals partaking in water sports and recreation (Agampodi et al., 2014; Katz et al., 2002; Ko et al., 2009; Lau et al., 2010; Morgan et al., 2002; Sejvar et al., 2003). Leptospirosis is regarded as the most widespread zoonotic disease (Evangelista and Coburn, 2010) and is reemerging in regions once thought to be relatively free of the pathogen, such as northern Sweden (Strand et al., 2015) (see Table 1 below).

\subsubsection{Symptomatology (morbidity and case-fatality ratios)}

The symptoms of leptospirosis vary from asymptomatic to a severe hemorrhagic and/or multi-organ disease. The severity of the disease depends on the Leptospira species (Alston, 1935) and the ability of the strain to cause infection. The disease can be divided in two stages; in the first stage (septicemic phase), leptospires multiply in the host's blood and other tissues and cause fever, chills, headache, anorexia, myalgia (mainly in calves) and nausea or fulminant cases, and in the immune phase conjunctival suffusion and jaundice. Headache, photophobia, nausea, retro-orbital pain may indicate the presence of Leptospira in the cerebrospinal fluid (Picardeau, 2013). Severe leptospirosis (Weil's disease or severe pulmonary hemorrhage syndrome) can develop after the septicemic phase. Weil's disease is characterized by hemorrhage, 
jaundice, and renal failure (Bharti et al., 2003), while severe pulmonary hemorrhage is linked to massive intraalveolar bleeding. Mortality due to these 2 syndromes may range from $5-15 \%$ and renal failure may affect $16-40 \%$ of cases. Pulmonary pathology may occur in $20-70 \%$ of the cases and symptoms may range from cough, dyspnea, hemoptysis, to respiratory distress syndrome (Adler and de la Peña-Moctezuma, 2010). Death can occur from kidney failure, pulmonary hemorrhage, or other serious multiorgan system dysfunction.

\subsection{Taxonomic Classification of the Agent(s)}

Leptospirosis is caused by spirochetes of the genus Leptospira, which currently comprises 35 species that are phylogenetically separated into three clusters: 13 pathogenic, 11 saprophytic, and 11 intermediate (Adler and de la Peña-Moctezuma, 2010; Thibeaux et al., 2018b; Thibeaux et al., 2018a). The etiologic agents of this disease are pathogenic and intermediate species of Leptospira, which comprise more than 260 serovars (Adler, 2015a). Pathogenic and intermediate clusters have been reported to cause infection and, in this Chapter, we will refer to them as "virulent" Leptospira. The organism is a thin spirochete of 0.1 to $0.2 \mu \mathrm{m}$ in diameter and 6 to $12 \mu \mathrm{m}$ in length, so it may even pass through $0.22 \mu \mathrm{m}$ filters. Hence $0.22 \mu \mathrm{m}$ prefiltration is often used to decontaminate Leptospira cultures from other bacteria (Evangelista and Coburn, 2010). It is a highly motile bacterium showing translational motility, travelling approximately $20 \mu \mathrm{m}$ in 2 to 3 seconds in ordinary media. It has been demonstrated that such a motility is due to its coiled periplasmic flagellum that rotates at the leading end, generating a helical wave that propels the cell by rolling in an direction opposite to that of the flagellar gyration (Goldstein and Charon, 1988, Picardeau et al., 2001).

\subsection{Transmission}

\subsubsection{Routes of transmission}

Leptospira, as a fragile spirochete, is not resistant to desiccation, so aqueous environments are necessary for survival and transmission among mammals sharing a common environment (Adler, 2015a). Transmission of Leptospira to susceptible hosts usually occurs through contact with urine or water sources contaminated with animal urine (Ko et al., 2009). Sick animals usually shed virulent leptospires during the immune phase and convalescence of the disease (asymptomatic carriers). Rodents, on the other hand, usually are resistant to disease, but can remain infected and act as continuous reservoirs, shedding infecting leptospires through urine to environment for life (Thiermann, 1981). Most mammals can carry leptospires with no signs of disease or only mild clinical manifestations. Such subclinical infections are caused mainly (but not exclusively) by host-adapted serovars. The three main environments indicating human transmission risks are water-based, rodent-borne and livestock/pet-borne environments.

\subsubsection{Human, animal, and environmental reservoirs}

Leptospirosis is primarily an animal disease affecting wild and domestic mammals. Acute leptospirosis in animals can present with the same clinical patterns as in humans, mostly in young animals. After the septicemic phase, once the circulating antibody titers have risen, pathogenic serovars of Leptospira usually accumulate in kidneys, inside the renal tubules; so that infected animals shed potentially infecting leptospires to the environment through their urine. It causes important losses to livestock operations (especially cattle and swine), mainly because of abortion and infertility. In dogs the disease shows at least three different pathologic syndromes: icteric syndrome, uremic syndrome and hemorrhagic syndrome (Adler and de la Peña-Moctezuma, 2010). Seroprevalence in cattle may be as high as $84 \%$ and in dogs 35\% (de Freitas et al., 2010, Ellis et al., 1986b, Oliveira Lavinsky et al., 2012, Schuller et al., 2015). Lower incidences have been found in other domestic animals among them sheep acting mainly as asymptomatic reservoirs (Cerri et al., 1996, Ellis et al., 1994, Lilenbaum et al., 2009); in horses the disease usually has a chronic course resulting in recurrent uveitis (ERU) being the main cause of equine blindness (Halliwell et al., 1985, Malalana et al., 2015, Wollanke et al., 2001). Cats are usually resistant to infection unless a concurrent immunosuppressive disease might be affecting them, such as feline leukemia virus or feline AIDS (Azocar-Aedo et al., 2014, Hartmann et al., 2013). Outbreaks of leptospirosis have also been described in wild animals such as sea lions in California (Avalos-Téllez et al., 2016, Colagross-Schouten et al., 2002, Prager et al., 2013). Other wild species such as rhinoceroses and wolves may suffer of acute leptospirosis, but probably only when kept in captivity (Neiffer et al., 2001). Rodents play an important role in transmission and are considered the principal reservoirs that maintain leptospires present in environment and the main source of infection to susceptible hosts such as pigs, dogs, zoo animals and humans (Athanazio et al., 2008, Costa et al., 2014, Haake and Levett, 2015). De Faria et al. (2008) reported that up to $80.3 \%$ of Norway rats (Rattus norvegicus), a species that spread almost all over the globe, were culture positive and $68.1 \%$ were shown positive by antibody titers of at least $1: 100$ in a microscopic agglutination test (MAT). Other species of wild mammals have been detected as leptospiral carriers (Andreoli et al., 2014, Duncan et al., 2012, Pinna et al., 2012, Scialfa et al., 2013). In France, seropositivity rates were found to range from 31\% in farmed American mink, 74\% in wild European mink and up to $89 \%$ in stone martens (Moinet et al., 2010). In the United Kingdom, seropositivity rates were $6.2 \%$ in water voles (Gelling et al., 2015). Bats from different continents have also been shown as carriers of different Leptospira species, with a variable excretion rates (from 6 to $45 \%$ ) (Dietrich et al., 2015). Most infected animals recover and become asymptomatic carriers for long periods of time, shedding leptospires through their urine (Della Rossa et al., 2016, Ko et al., 2009, Villanueva et al., 2014). Some serovars are adapted to a specific animal species, serovar Canicola to dogs (Morrison and Wright, 1976), serovar Hardjo to cattle (Ellis et al., 1986b), serovars Pomona and Bratislava to pigs (Ellis et al., 1986a; Stalheim, 
1968), serovar Pomona to horses (Halliwell et al., 1985, Verma et al., 2013a), serovar Ballum to mice (Carmona Gasca et al., 2013; da Silva et al., 2010; Brem et al., 1995), serovar Icterohaemorrhagiae to rats (Thiermann, 1981; Adler and de la Peña-Moctezuma, 2010). Except in specific endemic settings (Ganoza et al., 2010), chronic renal carriage in humans is very rare and does not significantly contribute to the epidemiology of leptospirosis. Human to human transmission is a very rare event and humans mostly acquire the disease directly from animals (i.e., contact with urine or tissues) or more frequently indirectly (i.e., contact with urine-contaminated water) (Koizumi et al., 2009, Ko et al., 2009).

\subsubsection{Incubation period}

Leptospirosis has a variable incubation period depending on virulence of the infecting strain, infecting dose and the patient susceptibility (Levett, 2001). Entrance of pathogenic Leptospira to susceptible hosts occurs through mucous membranes or skin abrasions (Adler and de la Peña-Moctezuma, 2010; Levett, 2001). Leptospires reach the bloodstream and replicate in the absence of specific antibodies (leptospiremia), disseminating to many tissues (Coutinho et al., 2014, Ko et al., 2009). This phase is called septicemic phase and typically is characterized by fever, myalgia, arthralgia, erythema and cephalgia (Alston, 1935) and lasting from three to ten days. After this phase, serum antibodies become elevated and leptospires correspondingly disappear from the bloodstream (Ko et al., 2009; Levett, 2001). Studies in animals, particularly hamsters, have revealed that most tissues are invaded, especially kidneys, where leptospires allocate into the renal tubules away from the circulating specific antibodies (Coutinho et al., 2014). Leptospires are subsequently shed to the environment via urine (leptospiruria). This second phase of the disease, in which leptospires are shed, is called the immune phase and can last for long periods of time, even for life in reservoir animals (Ko et al., 2009). Many of the severe symptoms of this phase of the disease may be due to immunopathology (Fraga et al., 2011).

\subsubsection{Period of communicability}

Although very rare cases of inter-human transmission have been suspected and reported, leptospirosis is not a contagious disease. Therefore, this section discusses communicability from the animal reservoir and human susceptibility. Three main factors intervene to define the period during which sick animals, asymptomatic carriers or reservoirs may shed infecting leptospires to the environment (Adler and de la Peña-Moctezuma, 2010; Holt et al., 2006).

1. Serovar virulence. Virulence obviously and directly relates to the infective dose. It has been shown that Leptospira serovars vary in their level of pathogenicity. There are differences in virulence (level of pathogenicity), even among isolates of the same serovar. Some extremely virulent serovars have an experimental $\mathrm{LD}_{50}$ of four or less bacteria (CFU) per animal in the hamster model (Sánchez,
2008; Watanabe et al., 2014). In any case, the infectious dose is crucial to the severity of the disease. Even though some species-adapted serovars may cause mild or no obvious signs of disease, they may still be shed to the environment through urine.

2. Immune status of the host. Animals that have never been in contact with a virulent Leptospira serovar, young or immunosuppressed individuals are more prone to acquire a severe clinical infection, relative to adults or immune competent individuals that develop a mild disease. Severe clinical infection may end in death of sick animals. Chronic carriers, in contrast, may shed infectious leptospires for long periods of time, even for life. Of note, leptospirosis immunity is both short lasting and serogroupspecific. People in hyperendemic areas may get leptospirosis several times, either from strains belonging to different serogroups or after postinfection immunity has declined.

3. The serovar - animal species relationship. It is well known that species-adapted serovars develop mild or subclinical infections in the corresponding animal species, frequently leading to chronic carriage in their animal host and chronic urinary shedding (Levett, 2001). In contrast, serovars non-adapted to the infected species usually produce severe or even fatal infections, but result in short-term excretion.

Depending on these three factors, an animal may, on the one hand, become severely sick and even die from the leptospiral infection, so that the period of shedding might be short or even non-existent. On the other hand, if the infection is not so severe as to kill the patient/animal, the relapse and recovery can lead to a state of chronicity and animals then become asymptomatic carriers for long periods of time and even for life (Adler, 2015a). Numbers shed in urine are rarely reported, but are usually high, e.g. Gillespie and Ryno reported a direct microscopic count of up to 108 leptospires per milliliter shed in cow's urine (Gillespie and Ryno, 1963).

\subsubsection{Population susceptibility}

As mentioned above, leptospirosis affects more than one million people a year worldwide, and almost 60,000 fatal cases per year (Costa et al., 2015; Ko et al., 2009). Farmers and suburban slum inhabitants are at the highest risk of infection (Costa et al., 2014), however there is one report suggesting that natural bodies of water in urban settings may pose higher risks of severe leptospirosis than rural ones (Ganoza et al., 2006). There have been reports of human leptospirosis outbreaks associated with urine contamination of water sources presenting a fatality rate of $8.6 \%$ (3 out of 35) (Cacciapuoti et al., 1987). Most outbreaks however are related to flooding following heavy exceptional or seasonal rainfall (Wynwood et al., 2014; Smith et al., 2013; Easton, 1999; Gaynor et al., 2007; Weinberger et al., 2014). However, there is at least one report where the main risk factor was the opposite, subnormal rainfall that may have contributed to the risk of exposure in military personnel exposed to contaminated 
water sources (Corwin et al., 1990). The environmental exposure is detailed in section 2. Of note, males are infected more frequently than females, possibly reflecting both an occupational nature of the transmission and sex- related susceptibility (Costa et al., 2014; Haake and Levett, 2015; Gomes et al., 2018). Global incidence rates are indicated in Table 1.

Table 1. Incidence of diagnosed disease for virulent Leptospira

\begin{tabular}{lccc}
\hline Geographical Area of Study & Gender & Incidence per & 100,000 Inhabitants \\
\cline { 1 - 3 } World-wide & Both & 1.03E+06 cases /year & Year of Data Collection \\
Africa & Female & 8.6 & 1970 to 2008 \\
Africa & Male & 25.5 & 1970 to 2008 \\
Americas & Female & 6.6 & 1970 to 2008 \\
Americas & Male & 23.3 & 1970 to 2008 \\
Asia and Oceania & Female & 10.9 & 1970 to 2008 \\
Asia and Oceania & Male & 37.5 & 1970 to 2008 \\
Europe & Female & 2.3 & 1970 to 2008 \\
Europe & Male & 7.8 & 1970 to 2008
\end{tabular}

Source: Costa et al., 2015

a per 100,000 inhabitants unless otherwise noted but, no data available for prevalence or seasonality

\subsection{Population and Individual Control Measures}

\subsubsection{Vaccines}

After the first isolation of Leptospira in Japan in 1914, Japanese researchers showed two years later that a phenolinactivated culture of a virulent Leptospira elicited immunity against infection in Guinea pigs (Ido et al., 1916; Adler, 2015b). To date, different methods for inactivation of leptospires for use as vaccines have been applied, these include formalin, phenol, ethanol, heat, freeze and thaw and radiation. After 100 years, the only licensed vaccines are whole Leptospira inactivated bacterins (Adler, 2015b). As leptospirosis is largely a zoonotic disease, it is important to consider animal immunization as part of a control strategy - hence the detailed discussion in this section on vaccines. Current practice should consider immunization of local animals, such as dogs, cattle and pigs.

Leptospirosis is considered a neglected disease, and the spirochete causing this disease, Leptospira, is very difficult to recover in culture. Only recently have molecular genetics tools been developed that are suitable for the study of this spirochete (Adler, 2015a;Evangelista and Coburn, 2010; Ko et al., 2009). These factors have contributed to a lag in the understanding of its virulence mechanisms, its immunogenic properties and finally a lag in the development of vaccines that may induce robust and lasting protection (Adler, 2015b; Evangelista and Coburn, 2010).

\subsubsection{Global coverage and future prospects}

To date, available Leptospira vaccines only provide a short lasting and serogroup-specific immunity. Problems with components of the culture media and reactogenicity have also been suspected, although not demonstrated (Benbrik et al., 2001). Therefore, such bacterins have not been widely used in humans. However human bacterin vaccines have been used successfully in several regions, including China, Japan, Cuba, and Europe (Verma et al., 2013b; Zamora et al., 2005), notably to prevent occupational leptospirosis in sewage-workers (De Serres et al., 1995; Nardone et al., 2004). Importantly, animal vaccination might still prove useful in reducing leptospirosis burden in humans, by decreasing the environmental contamination. In this regard, dog vaccination is routinely performed in a number of countries, aiming at protecting both the dog and its owner (Gay et al., 2014). Livestock vaccination is widely implemented in New Zealand and correlated with a significant decrease in human cases (Thornley et al., 2002). Further details on vaccines are presented in Appendix A.

\subsubsection{Hygiene measures}

Currently, implementing rodent control through improved sanitation and food residuals management seems the most effective measures to limit leptospirosis. Farmers and other professionals in occupations at risk should use protective gear (apron, gloves, boots and protective mask), e.g. in abattoirs or when using high pressure water (for cleaning) to avoid infection by aerosolized animal urine. Additionally, animal vaccination may reduce leptospiral shedding (Subharat et al., 2012). For workers exposed to municipal wastewaters (e.g. sewage workers), vaccination, even in developed regions would seem appropriate for risk 
management (De Serres et al., 1995), however vaccines for humans are available only in a few countries.

\subsection{Environmental Occurrence and Persistence}

Studies of virulent Leptospira in the environment are very limited, mainly because it is difficult to isolate these spirochetes from surface waters or soil without contamination with saprophytic Leptospira. However, there is a growing interest in understanding the lifestyle and survival capabilities of virulent Leptospira in the environment. In addition, genomic studies suggest that virulent Leptospira evolved from an environmental (freeliving) Leptospira present in water or mud, similarly to the contemporary members of the saprophytic cluster (such as L. biflexa) (Saito et al., 2013; Thibeaux et al., 2018b; Thibeaux et al., 2018a). There seems to be some evolutionary variation within virulent leptospires; some species (such as L. interrogans) have retained genes associated to environmental survival whereas other virulent members (such as L. borgpetersenii) seem to have lost these genes. These findings have been corroborated by in vitro experiments showing that $L$. interrogans survives better in distilled water than $L$. borgpetersenii (Bulach et al., 2006, Picardeau et al., 2008), which may imply that $L$. borgpetersenii is not transmitted by water but rather relies on direct host-to-host transmission (Bulach et al., 2006).

Leptospiral survival in water is bolstered by viscous material, such as agar, which possibly translates to biofilm in natural environments. Some strains of virulent Leptospira are able to produce biofilms when incubated in fresh water, even in the absence of nutrients (Barragan et al., 2011; Ristow et al., 2008). Furthermore L. interrogans (pathogenic cluster) has been found in nature associated with biofilms formed by environmental bacteria (Vinod Kumar et al., 2015a). Some virulent Leptospira are able to produce biofilm when incubated in distilled water (low nutrient conditions) and appear sense the presence of nutrients, such as fatty acids, which triggers release of leptospiral cells from the biofilm (Barragan et al., 2011). It has been observed that biofilm-borne leptospiral cells display a five- to six-fold increase in antibiotic tolerance (Vinod Kumar et al., 2016a). It has also been speculated that biofilms protect pathogenic Leptospira against other toxic compounds and stressors in the environment. Taken together, Leptospira survival in the environment seems to be favored by biofilm formation, which could contribute to disease transmission among risk groups such as sewage and agricultural workers (Della Rossa et al., 2016; Ganoza et al., 2006; Koizumi et al., 2009; Trueba et al., 2004).

Soil may also play a role in environmental survival. Some researchers have shown that Leptospira survived in the wet soil on dry days and appeared in surface water on rainy days, suggesting that soil could be a reservoir for leptospires in the environment (Saito et al., 2013; Thibeaux et al., 2017). Even though leptospires are considered fragile spirochetes, studies have shown that they can survive and even maintain their virulence for up to 20 months despite unfavorable conditions, such as cold and nutrient-poor acidic waters (Andre-Fontaine et al., 2015). However, there is limited knowledge about possible differences in the nutritional requirements of saprophytic and virulent species and about ability of virulent leptospires to multiply in surface water or soils. General data on the occurrence of leptospires in the environment is presented in Tables 2-5.

Table 2. Pathogenic Leptospira occurrence in sewage and wastewaters

\begin{tabular}{|c|c|c|c|c|c|}
\hline Area & Year & Sample Description & $\begin{array}{c}\text { Occurrence } \\
\text { Percent Positive } \\
\text { (Sample Numbers) }\end{array}$ & Detection Method & Reference \\
\hline $\begin{array}{l}\text { Brazil } \\
\text { (Salvador, } \\
\text { Pau da } \\
\text { Lima) }\end{array}$ & $\begin{array}{l}2011 \text { to } \\
2012 \\
\text { (July to } \\
\text { January) }\end{array}$ & Sewage Water & $\begin{array}{c}36 \% \\
(121 / 335)\end{array}$ & $\begin{array}{l}\text { LipL32 qPCR on } 40 \mathrm{~mL} \\
\text { water sample }\end{array}$ & $\begin{array}{c}\text { Casanovas-Massana } \\
\text { et al., } 2018\end{array}$ \\
\hline $\begin{array}{l}\text { Colombia } \\
\text { (Cordoba) }\end{array}$ & $\begin{array}{l}2009 \text { to } \\
2011\end{array}$ & Waste water (from pig stable) & $\begin{array}{l}5.56 \% \\
(1 / 18)\end{array}$ & $\begin{array}{l}\text { Culture enrichment } \\
0.5 \mathrm{~mL} \text { with and } \\
\text { without filtration } \\
\text { through } 0.45 \mu \mathrm{m} \text { filter }\end{array}$ & $\begin{array}{l}\text { Calderon et al., } \\
\qquad 2014 ;\end{array}$ \\
\hline $\begin{array}{l}\text { UK } \\
\text { (London) }\end{array}$ & 1977 & $\begin{array}{c}\text { Sewage } \\
\text { (cattle market and farms) }\end{array}$ & $\begin{array}{l}100 \% \\
(2 / 2)\end{array}$ & $\begin{array}{c}\text { Culture of } 20 \mathrm{~mL} \\
\text { serogroup Tarassovi } \\
\text { identified }\end{array}$ & $\begin{array}{l}\text { Coghlan and } \\
\text { Kmety, } 1987\end{array}$ \\
\hline $\begin{array}{l}\text { UK } \\
\text { (Oxford) }\end{array}$ & $\begin{array}{l}1980 \text { to } \\
1981\end{array}$ & Sewage and sewage sludges & $\begin{array}{c}15.9 \% \\
(30 / 189)\end{array}$ & $\begin{array}{c}\text { Culture }^{\text {a }} 20 \mathrm{ml} \text { reduced } \\
\text { to } 0.2 \mathrm{ml} \\
\text { Via } \\
\text { centrifugation/filtration } \\
\text { tarrassovi serotype } \\
\text { identified }\end{array}$ & Jones et al., 1981 \\
\hline
\end{tabular}

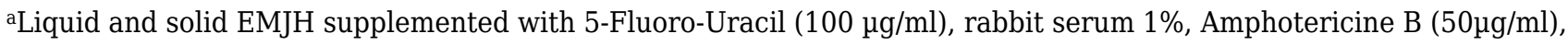
Sulphatiazole $(50 \mathrm{mg} / \mathrm{L})$, neomycin sulphate $(5 \mathrm{mg} / \mathrm{L})$, actidione $(0.5 \mathrm{mg} / \mathrm{L})$ and incubated at $29^{\circ} \mathrm{C}$. Identification by serological typing. 
Table 3. Pathogenic Leptospira occurrence in water samples

\begin{tabular}{|c|c|c|c|c|c|}
\hline Area & Year & Sample Description & $\begin{array}{c}\text { Occurrence } \\
\text { Percent Positive } \\
\text { (Sample } \\
\text { Numbers) } \\
\end{array}$ & Detection Method & Reference \\
\hline $\begin{array}{l}\text { Brazil } \\
\text { (Pelotas) }\end{array}$ & $\mathrm{NR}^{\mathrm{a}}$ & $\begin{array}{c}\text { Stagnant Water } \\
\text { (abandoned swimming pool } \\
\text { with dead possums and rats) }\end{array}$ & $\begin{array}{c}100 \% \\
(1 / 1)\end{array}$ & Culture (Few Drops) & Forster et al., 2013 \\
\hline $\begin{array}{l}\text { Brazil } \\
\text { (Rio de } \\
\text { Janeiro, } \\
\text { Petropolis) }\end{array}$ & $\begin{array}{l}2009 \\
\text { (May to } \\
\text { July) }\end{array}$ & $\begin{array}{l}\text { Community water supplies, } \\
\text { small lakes, and surface water }\end{array}$ & $\begin{array}{c}0.1 \% \\
(1 / 100)\end{array}$ & $\begin{array}{c}\text { Multiplex PCR on } 125 \\
\text { mL } \\
\text { lipL-32 and 16srRNA } \\
\text { both genes amplified in } \\
\text { pathogenic species }\end{array}$ & $\begin{array}{l}\text { Vital-Brazil et al., } \\
2010\end{array}$ \\
\hline $\begin{array}{l}\text { Brazil } \\
\text { (Salvador, } \\
\text { Pau da Lima) }\end{array}$ & $\begin{array}{l}2011 \text { to } \\
2012 \\
\text { (July to } \\
\text { January) }\end{array}$ & Standing Water & $\begin{array}{c}34 \% \\
(82 / 250)\end{array}$ & $\begin{array}{l}\text { lipL32 qPCR on } 40 \mathrm{~mL} \\
\text { water sample }\end{array}$ & $\begin{array}{c}\text { Casanovas-Massana } \\
\text { et al., } 2018\end{array}$ \\
\hline $\begin{array}{l}\text { Chile } \\
\text { (Los Rios) }\end{array}$ & $\begin{array}{l}2010 \text { to } \\
2012 \\
\text { (November } \\
\text { to April) }\end{array}$ & Puddles & $\begin{array}{c}19.3 \% \\
(36 / 306)\end{array}$ & $\begin{array}{l}\text { lipL32-PCR on } 50 \mathrm{~mL} \text { to } \\
\text { 1.0L water }\end{array}$ & $\begin{array}{l}\text { Muñoz-Zanzi et al., } \\
2014\end{array}$ \\
\hline $\begin{array}{l}\text { Chile } \\
\text { (Los Rios) }\end{array}$ & $\begin{array}{l}2010 \text { to } \\
2012 \\
\text { (November } \\
\text { to April) }\end{array}$ & Water in open containers & $\begin{array}{l}45.5 \% \\
(10 / 22)\end{array}$ & $\begin{array}{l}\text { lipL32-PCR on } 50 \mathrm{~mL} \text { to } \\
\text { 1.0L water }\end{array}$ & $\begin{array}{l}\text { Muñoz-Zanzi et al., } \\
2014\end{array}$ \\
\hline $\begin{array}{l}\text { Chile } \\
\text { (Los Rios) }\end{array}$ & $\begin{array}{l}2010 \text { to } \\
2012 \\
\text { (November } \\
\text { to April) }\end{array}$ & Water Canals/Rivers & $\begin{array}{c}3.9 \% \\
(4 / 103)\end{array}$ & $\begin{array}{l}\text { lipL32-PCR on } 50 \mathrm{~mL} \text { to } \\
\text { 1.0L water }\end{array}$ & $\begin{array}{c}\text { Muñoz-Zanzi et al., } \\
2014\end{array}$ \\
\hline $\begin{array}{l}\text { Chile } \\
\text { (Los Rios) }\end{array}$ & $\begin{array}{l}2010 \text { to } \\
2012 \\
\text { (October to } \\
\text { April) }\end{array}$ & Puddles & $\begin{array}{c}27.3 \% \\
(84 / 208)\end{array}$ & $\begin{array}{l}\text { PCR and sequencing on } \\
50 \mathrm{~mL} \text { to } 1 \mathrm{~L} \text { water }\end{array}$ & Mason et al., 2016 \\
\hline $\begin{array}{l}\text { Chile } \\
\text { (Los Rios) }\end{array}$ & $\begin{array}{l}2010 \text { to } \\
2012 \\
\text { (October to } \\
\text { April) }\end{array}$ & Water in open containers & $\begin{array}{c}14.4 \% \\
(28 / 194)\end{array}$ & $\begin{array}{l}\text { PCR and sequencing on } \\
50 \mathrm{~mL} \text { to } 1 \mathrm{~L} \text { water }\end{array}$ & Mason et al., 2016 \\
\hline $\begin{array}{l}\text { Chile } \\
\text { (Los Rios) }\end{array}$ & $\begin{array}{l}2010 \text { to } \\
2012 \\
\text { (October to } \\
\text { April) }\end{array}$ & Water Canals/Rivers & $\begin{array}{c}9.7 \% \\
(13 / 134)\end{array}$ & $\begin{array}{l}\text { PCR and sequencing on } \\
50 \mathrm{~mL} \text { to } 1 \mathrm{~L} \text { water }\end{array}$ & Mason et al., 2016 \\
\hline $\begin{array}{l}\text { Colombia } \\
\text { (Cordoba) }\end{array}$ & $\begin{array}{c}2009 \text { to } \\
2011\end{array}$ & Well Water & $\begin{array}{c}0 \% \\
(0 / 18)\end{array}$ & $\begin{array}{l}\text { Culture enrichment } \\
0.5 \mathrm{~mL} \text { with and } \\
\text { without filtration } \\
\text { through } 0.45 \mu \mathrm{m} \text { filter }\end{array}$ & $\begin{array}{l}\text { Calderon et al., } \\
2014\end{array}$ \\
\hline $\begin{array}{l}\text { Colombia } \\
\text { (Cordoba) }\end{array}$ & $\mathrm{NA}^{\mathrm{b}}$ & Untreated water samples & $\begin{array}{c}0 \% \\
(0 / 13)\end{array}$ & $\begin{array}{l}15 \mathrm{~mL} \text { water samples } \\
\text { collected on farms } \\
\text { Centrifuged } 14,000 \\
\text { rpm / } 5 \text { min. Pellet } \\
\text { washed by PBS. PCR } \\
\text { and sequencing. }\end{array}$ & $\begin{array}{l}\text { Ensuncho-Hoyos et } \\
\text { al., } 2017\end{array}$ \\
\hline
\end{tabular}




\begin{tabular}{|c|c|c|c|c|c|}
\hline Area & Year & Sample Description & $\begin{array}{c}\text { Occurrence } \\
\text { Percent Positive } \\
\text { (Sample } \\
\text { Numbers) } \\
\end{array}$ & Detection Method & Reference \\
\hline $\begin{array}{l}\text { France } \\
\text { (Lyon) }\end{array}$ & $\begin{array}{c}2008 \\
\text { (Spring) }\end{array}$ & Water & $\begin{array}{l}6.38 \% \\
(3 / 47)\end{array}$ & $\begin{array}{l}\text { qPCR on } 50 \mathrm{~mL} \text { of } \\
\text { water } \\
103 \text { to } 104 \text { genome- } \\
\text { equivalents/mL }\end{array}$ & Vein et al., 2012 \\
\hline $\begin{array}{l}\text { India } \\
\text { (Nicobar and } \\
\text { Andaman } \\
\text { Islands) }\end{array}$ & 2012 & Urban Water Samples & $\begin{array}{c}9.7 \% \\
(11 / 113)\end{array}$ & $\begin{array}{l}\text { PCR on } 20 \mathrm{~mL} \text { water } \\
\text { sample, Centrifuged } \\
8,000 \mathrm{~g} \text { for } 10 \mathrm{~min} . \\
\text { DNA extracted from } \\
\text { pellet }\end{array}$ & Lall et al., 2016 \\
\hline $\begin{array}{l}\text { India } \\
\text { (Nicobar and } \\
\text { Andaman } \\
\text { Islands) }\end{array}$ & 2012 & Rural Water Samples & $\begin{array}{c}6.7 \% \\
(9 / 133)\end{array}$ & $\begin{array}{l}\text { PCR on } 20 \mathrm{~mL} \text { water } \\
\text { sample, Centrifuged } \\
8,000 \mathrm{~g} \text { for } 10 \mathrm{~min} . \\
\text { DNA extracted from } \\
\text { pellet }\end{array}$ & Lall et al., 2016 \\
\hline $\begin{array}{l}\text { India } \\
\text { (Nicobar and } \\
\text { Andaman } \\
\text { Islands) }\end{array}$ & 2012 & Paddy Fields & $\begin{array}{c}15.9 \% \\
(18 / 113)\end{array}$ & $\begin{array}{l}\text { PCR on } 20 \mathrm{~mL} \text { water } \\
\text { sample, Centrifuged } \\
8,000 \mathrm{~g} \text { for } 10 \mathrm{~min} . \\
\text { DNA extracted from } \\
\text { pellet }\end{array}$ & Lall et al., 2016 \\
\hline $\begin{array}{l}\text { Island of St. } \\
\text { Kitts }\end{array}$ & NA & $\begin{array}{c}\text { Water } \\
\text { (Environmental water: ponds, } \\
\text { puddles, water dams, } \\
\text { mountain spring and stream) }\end{array}$ & $\begin{array}{c}18.18 \% \\
(8 / 44)\end{array}$ & $\begin{array}{c}\text { qPCR on } 300 \mathrm{~mL} \\
\text { environmental water } \\
\text { sample } \\
\text { (20.6 to } 56 \text { genomes } \\
\text { per } 300 \mathrm{~mL})\end{array}$ & Rawlins et al., 2014 \\
\hline Italy & 2005 & Water (From toilet and tap) & $\begin{array}{l}50 \% \\
(2 / 4)\end{array}$ & $\begin{array}{l}\text { Environmental source } \\
\text { tracking after fatal } \\
\text { case }\end{array}$ & Luchini et al., 2008 \\
\hline Malaysia & $\begin{array}{c}2012 \text { to } \\
2013 \\
\text { (December } \\
\text { to } \\
\text { November) }\end{array}$ & Water & $\begin{array}{c}0 \% \\
(0 / 72)\end{array}$ & $\begin{array}{c}40 \mathrm{~mL} \text { of water filtered } \\
\text { through } 0.2 \mu \mathrm{m} \text {, filtrate } \\
\text { centrifuged } \\
4,000 \mathrm{~g} / 27^{\circ} \mathrm{C} / 20 \mathrm{~min} \\
\text { before culture. }\end{array}$ & Azali et al., 2016 \\
\hline $\begin{array}{l}\text { Malaysia } \\
\text { (Lubuk, Yu, } \\
\text { Pahang) }\end{array}$ & 2011 & Stagnant Water & $\begin{array}{l}100 \% \\
(8 / 8)\end{array}$ & $\begin{array}{l}\text { PCR on } 100 \mathrm{~mL} \text { of } \\
\text { water }\end{array}$ & Sapian et al., 2012 \\
\hline $\begin{array}{l}\text { Malaysia } \\
\text { (Kelantan) }\end{array}$ & $\begin{array}{c}2016 \\
\text { (June to } \\
\text { September) }\end{array}$ & Water & $\begin{array}{c}0 \% \\
(0 / 21)\end{array}$ & $\begin{array}{l}100 \mathrm{~mL} \text { sample, } \\
\text { cultured } 1 \mathrm{~mL} \text { filtered } \\
\text { through } 0.22 \mu \mathrm{m} \text { with } 5 \text { - } \\
\text { Fluoro-Uracil }\end{array}$ & $\begin{array}{l}\text { Mohd Ali et al., } \\
2018\end{array}$ \\
\hline $\begin{array}{l}\text { Malaysia } \\
\text { (Kelantan } \\
\text { and } \\
\text { Terengganu) }\end{array}$ & $\begin{array}{c}2009 \\
\text { (April) }\end{array}$ & $\begin{array}{l}\text { Water after culture pre- } \\
\text { enrichement }\end{array}$ & $\begin{array}{c}6.78 \% \\
(12 / 177)\end{array}$ & $\begin{array}{c}\text { PCR after enrichment } \\
\text { in culture, 5-10 drops } \\
\text { used }\end{array}$ & Ridzlan et al., 2010 \\
\hline $\begin{array}{l}\text { Malaysia } \\
\text { (Sarawak) }\end{array}$ & $\begin{array}{l}2014 \text { to } \\
2015 \\
\text { (April to } \\
\text { February) }\end{array}$ & $\begin{array}{c}\text { Water } \\
\text { (Drain effluent, river, lake, } \\
\text { puddle) }\end{array}$ & $\begin{array}{l}1.96 \% \\
(6 / 324)\end{array}$ & $\begin{array}{c}\text { PCR on } 50 \mathrm{~mL} \text { water } \\
\text { sample }\end{array}$ & Pui et al., 2017b \\
\hline $\begin{array}{l}\text { Malaysia } \\
\text { (Terengganu) }\end{array}$ & $\begin{array}{c}2012 \\
\text { (February } \\
\text { and March) }\end{array}$ & Water & $\begin{array}{c}7.5 \% \\
(3 / 40)\end{array}$ & $\begin{array}{l}\text { Culture (EMJH media) } \\
\text { and PCR } \\
2.5 \mathrm{ml} \text { of } 0.22 \mu \mathrm{m} \\
\text { filtrated water or pellet } \\
\text { of } 985 \mathrm{ml}\end{array}$ & Ismail et al., 2014 \\
\hline $\begin{array}{l}\text { New } \\
\text { Caledonia } \\
\text { (North } \\
\text { province } \\
\text { regions) }\end{array}$ & $\begin{array}{l}2016 \\
\text { (March to } \\
\text { June) }\end{array}$ & Water & $\begin{array}{c}0 \% \\
(0 / 10)\end{array}$ & $\begin{array}{l}\text { PCR/Viability-PCR on } \\
10 \text { mL of water } \\
\text { Linked the identity of } \\
\text { environmental } \\
\text { Leptospira to human } \\
\text { infecting strain }\end{array}$ & $\begin{array}{l}\text { Thibeaux et al., } \\
2017\end{array}$ \\
\hline
\end{tabular}




\begin{tabular}{|c|c|c|c|c|c|}
\hline Area & Year & Sample Description & $\begin{array}{c}\text { Occurrence } \\
\text { Percent Positive } \\
\text { (Sample } \\
\text { Numbers) } \\
\end{array}$ & Detection Method & Reference \\
\hline $\begin{array}{l}\text { Russia } \\
\text { (lake Nero, } \\
\text { Yaroslav } \\
\text { region) }\end{array}$ & $\begin{array}{c}1974 \\
\text { (June to } \\
\text { September) }\end{array}$ & $\begin{array}{c}\text { marsh and bank of lake } \\
\text { (moisture: } 69.5 \text { to } 70.3 \% \text {, } \\
\text { pH } 7.4 \text { to } 7.8 \text { ) }\end{array}$ & $\begin{array}{c}1.1 \% \\
(7 / 630)\end{array}$ & $\begin{array}{l}1 \mathrm{~g} \text { sample suspended } \\
\text { into } 5 \mathrm{ml} \\
\text { Inoculation to hamsters } \\
\text { Isolated } 4 \text { serogroups } \\
\text { grippotyphosa and } 1 \\
\text { serogroup hebdomadis }\end{array}$ & $\begin{array}{c}\text { Karaseva et al., } \\
1977\end{array}$ \\
\hline $\begin{array}{l}\text { Thailand } \\
\text { (Bangkok) }\end{array}$ & $\begin{array}{c}2011 \\
\text { (November) }\end{array}$ & River Water & $\begin{array}{l}0 \% \\
(0 / 2)\end{array}$ & $\begin{array}{c}1.5-6 \mathrm{~L} \\
\text { qPCR } \\
\text { Bacteria collected on } \\
0.2 \mu \mathrm{m} \text { filter membrane }\end{array}$ & $\begin{array}{l}\text { Chaturongkasumrit } \\
\text { et al., } 2013\end{array}$ \\
\hline $\begin{array}{l}\text { Thailand } \\
\text { (Bangkok) }\end{array}$ & $\begin{array}{c}2011 \\
\text { (November) }\end{array}$ & Flood Water & $\begin{array}{l}8.33 \% \\
(1 / 12)\end{array}$ & $\begin{array}{c}1.5 \text { to } 6 \mathrm{~L} \\
\text { qPCR } \\
\text { Bacteria collected on } \\
0.2 \mu \mathrm{m} \text { filter membrane } \\
\text { (Single positive from } \\
\text { urban residential area, } \\
\text { sample was turbid with } \\
\text { pH 8.05, Vibrio } \\
\text { cholerae detected) }\end{array}$ & $\begin{array}{l}\text { Chaturongkasumrit } \\
\text { et al., } 2013\end{array}$ \\
\hline $\begin{array}{l}\text { Thailand } \\
\text { (Bangkok } \\
\text { province, } \\
\text { Don Muang } \\
\text { district and } \\
\text { Nakhon } \\
\text { Pathom } \\
\text { province) }\end{array}$ & $\begin{array}{l}2011 \\
\text { (November } \\
\text { and } \\
\text { December) }\end{array}$ & Floodwater & $\begin{array}{c}0.9 \% \\
(1 / 110)\end{array}$ & $\begin{array}{c}\text { PCR and Culture on } \\
100 \mathrm{~mL} \text { of flood water } \\
\text { (50 mL for PCR, } 50 \mathrm{~mL} \\
\text { for culture) }\end{array}$ & $\begin{array}{l}\text { Thaipadungpanit et } \\
\text { al., } 2013\end{array}$ \\
\hline $\begin{array}{l}\text { Thailand } \\
\text { (Khon Kaen } \\
\text { and Nakhon } \\
\text { Ratchasima } \\
\text { Province) }\end{array}$ & $\begin{array}{l}2005 \text { to } \\
2006 \\
\text { (Nov to } \\
\text { Jan) }\end{array}$ & Water & $\begin{array}{c}23 \% \\
(23 / 100)\end{array}$ & Duplex PCR & $\begin{array}{c}\text { Tansuphasiri et al., } \\
2006\end{array}$ \\
\hline $\begin{array}{l}\text { Thailand } \\
\text { (Nan } \\
\text { Province) }\end{array}$ & $\begin{array}{l}2013 \text { to } \\
2016\end{array}$ & Water & $\begin{array}{l}21.4 \% \\
(3 / 14)\end{array}$ & $\begin{array}{c}\text { Rrs nested PCR and } \\
\text { MLST performed on } 50 \\
\text { mL of water. } \\
\text { Underground water } \\
\text { source used in animal } \\
\text { husbandry, } \\
\text { drinking/cleaning pens, } \\
\text { and/or rice fields }\end{array}$ & $\begin{array}{l}\text { Kurilung et al., } \\
\qquad 2017\end{array}$ \\
\hline $\begin{array}{l}\text { USA } \\
\text { (IL) }\end{array}$ & $\begin{array}{l}1998 \\
\text { (July) }\end{array}$ & $\begin{array}{l}\text { Water from coastal and non- } \\
\text { coastal areas } \\
\text { Lake Springfield } \\
\text { (Triathlon) }\end{array}$ & $\begin{array}{l}3.7 \% \\
(1 / 27)\end{array}$ & PCR & Morgan et al., 2002 \\
\hline
\end{tabular}


Table 4. Pathogenic Leptospira occurrence in soil, soil and water, and misc.

\begin{tabular}{|c|c|c|c|c|c|}
\hline Area & Year & Sample Description & $\begin{array}{c}\text { Occurrence } \\
\text { Percent } \\
\text { Positive } \\
\text { (Sample } \\
\text { Numbers) } \\
\end{array}$ & Detection Method & $\mathbf{R E F}$ \\
\hline $\begin{array}{l}\text { India } \\
\text { (Archipelago } \\
\text { of Andaman } \\
\text { and } \\
\text { Nicobar) }\end{array}$ & $\mathrm{NR}^{\mathrm{a}}$ & $\begin{array}{l}\text { Waterlogged paddy } \\
\text { field soil }\end{array}$ & $\begin{array}{c}60 \% \\
(6 / 10)\end{array}$ & $\begin{array}{l}\text { PCR on five sterile } \\
\text { glass rods (buried } \\
\text { up to } 3 \text { " deep in } \\
\text { different } \\
\text { waterlogged paddy } \\
\text { field soils and } \\
\text { allowed to rest for } \\
48 \mathrm{~h} \text { ) }\end{array}$ & Vinod Kumar et al., 2015b \\
\hline $\begin{array}{l}\text { India } \\
\text { (Nicobar } \\
\text { and } \\
\text { Andaman } \\
\text { Islands) }\end{array}$ & $\begin{array}{c}2014 \\
\text { (July to August) }\end{array}$ & $\begin{array}{c}\text { Paddy field Water and } \\
\text { Leaves }\end{array}$ & $\begin{array}{c}24 \% \\
(34 / 142)\end{array}$ & $\begin{array}{c}\text { PCR on sterile } \\
\text { glass slides } \\
\text { incubated for } 48 \mathrm{~h} \\
\text { in different sources } \\
\text { of water. Paddy } \\
\text { leaves were } \\
\text { collected and cut to } \\
1 \mathrm{~cm} \text { in length at } \\
\text { air-liquid } \\
\text { interphase }\end{array}$ & Vinod Kumar et al., 2016a \\
\hline $\begin{array}{l}\text { Japan } \\
\text { (Hokkaido } \\
\text { and } \\
\text { Okinawa) }\end{array}$ & $\begin{array}{l}2014 \text { to } 2016 \\
\text { (July to April) }\end{array}$ & Soil & $\begin{array}{c}9.1 \% \\
(12 / 132)\end{array}$ & $\begin{array}{c}20 \mathrm{~g} \text { of soil, culture } \\
\text { with STAFF and } \\
16 \mathrm{~S} \text { rDNA for } \\
\text { identification }\end{array}$ & Masuzawa et al., 2018 \\
\hline Malaysia & $\begin{array}{l}2012 \text { to } 2013 \\
\text { (December to } \\
\text { November) }\end{array}$ & Soil & $\begin{array}{l}1.39 \% \\
(1 / 72)\end{array}$ & $\begin{array}{l}\text { No sample volume } \\
\text { for soil } \\
\text { soil resuspended } \\
\text { with sterile water, } \\
\text { supernatant } \\
\text { filtered through } \\
0.2 \mu \mathrm{m} \text { before } \\
\text { culture. }\end{array}$ & Azali et al., 2016 \\
\hline $\begin{array}{l}\text { Malaysia } \\
\text { (Kelantan) }\end{array}$ & $\begin{array}{c}2016 \\
\text { (June to } \\
\text { September) }\end{array}$ & Soil & $\begin{array}{l}33.3 \% \\
(7 / 21)\end{array}$ & $\begin{array}{l}20 \mathrm{~g} \text { soil sample, } \\
\text { cultured } 1 \mathrm{~mL} \\
\text { washings filtered } \\
\text { through } 0.22 \mu \mathrm{m} \\
\text { with } 5 \text {-Fluoro- } \\
\text { Uracil }\end{array}$ & Mohd Ali et al., 2018 \\
\hline $\begin{array}{l}\text { Malaysia } \\
\text { (20 miles } \\
\text { around } \\
\text { Kuala } \\
\text { Lumpur) }\end{array}$ & 1961 to 1962 & Water and Soil & $\begin{array}{c}2.9 \% \\
(397 / 13,848)\end{array}$ & $\begin{array}{c}1 \text { to } 5 \mathrm{ml} \text { of water } \\
0.5 \mathrm{ml} \text { washing of } \\
\text { topsoil } \\
\text { Inoculation to } \\
\text { hamsters/guinea } \\
\text { pigs } \\
\text { serogroup Pomona } \\
\text { isolated }^{\mathrm{b}}\end{array}$ & Baker and Baker, 1970 \\
\hline $\begin{array}{l}\text { Malaysia } \\
\text { (Lubuk, Yu, } \\
\text { Pahang) }\end{array}$ & 2011 & Surface Soil & $\begin{array}{l}50 \% \\
(2 / 4)\end{array}$ & PCR of $100 \mathrm{~g}$ of soil & Sapian et al., 2012 \\
\hline $\begin{array}{l}\text { Malaysia } \\
\text { (Lubuk, Yu, } \\
\text { Pahang) }\end{array}$ & 2011 & Deep Soil $(30 \mathrm{~cm})$ & $\begin{array}{c}12 \% \\
(3 / 25)\end{array}$ & PCR of $100 \mathrm{~g}$ of soil & Sapian et al., 2012 \\
\hline $\begin{array}{l}\text { Malaysia } \\
\text { (Sarawak) }\end{array}$ & $\begin{array}{l}2014 \text { to } 2015 \\
\text { (April to } \\
\text { February) }\end{array}$ & $\begin{array}{l}\text { Surroundings of } \\
\text { housing areas, } \\
\text { landfills, open field, } \\
\text { and lake soil }\end{array}$ & $\begin{array}{c}11.6 \% \\
(34 / 292)\end{array}$ & PCR on $20 \mathrm{~g}$ & Pui et al., 2017a \\
\hline
\end{tabular}




\begin{tabular}{|c|c|c|c|c|c|}
\hline Area & Year & Sample Description & $\begin{array}{c}\text { Occurrence } \\
\text { Percent } \\
\text { Positive } \\
\text { (Sample } \\
\text { Numbers) } \\
\end{array}$ & Detection Method & REF \\
\hline $\begin{array}{l}\text { New } \\
\text { Caledonia } \\
\text { (North } \\
\text { province } \\
\text { regions) }\end{array}$ & $\begin{array}{c}2016 \\
\text { (March to June) }\end{array}$ & Soil & $\begin{array}{l}56.69 \% \\
(30 / 52)\end{array}$ & $\begin{array}{l}\text { PCR/Viability-PCR } \\
\text { on } 250 \text { mg soil } \\
\text { Pathogenic } \\
\text { leptospires were } \\
\text { alive and present in } \\
\text { soils several weeks } \\
\text { after the infecting } \\
\text { event }\end{array}$ & Thibeaux et al., 2017 \\
\hline $\begin{array}{l}\text { New } \\
\text { Caledonia } \\
\text { (North } \\
\text { province } \\
\text { regions) }\end{array}$ & $\begin{array}{c}2016 \\
\text { (March to June) }\end{array}$ & Vegetal Float debris & $\begin{array}{l}12.2 \% \\
(2 / 11)\end{array}$ & $\begin{array}{c}\text { PCR/Viability-PCR } \\
\text { on } 250 \text { mg vegetal } \\
\text { debris }\end{array}$ & Thibeaux et al., 2017 \\
\hline $\begin{array}{l}\text { Philippines } \\
\text { (Leyte } \\
\text { Province) }\end{array}$ & $\begin{array}{c}2014 \\
\text { (January) }\end{array}$ & Wet Soil & $\begin{array}{c}48 \% \\
(11 / 23)\end{array}$ & $\begin{array}{l}\text { PCR and culture } \\
\text { enrichment on } 10 \mathrm{~g} \\
\text { of wet soil } \\
\text { (16S rRNA gene } \\
\text { sequence similar to } \\
\text { L. kmetyi) }\end{array}$ & Saito et al., 2014 \\
\hline $\begin{array}{l}\text { Poland } \\
\text { (Lublin } \\
\text { province) }\end{array}$ & 2010 to 2013 & Water and Soil & $\begin{array}{l}0.94 \% \\
(2 / 212)\end{array}$ & $\begin{array}{l}\text { Traditional and } \\
\text { Nested PCR } \\
\text { targeting lipL-32 } \\
\text { (5L of water and } \\
\text { soils were collected } \\
\text { in 50mL falcon } \\
\text { tube) }\end{array}$ & Wojcik-Fatla et al., 2014 \\
\hline $\begin{array}{l}\text { Taiwan } \\
\text { (Yunlin, } \\
\text { Chiayi, } \\
\text { Tainan) }\end{array}$ & $\begin{array}{l}2010 \\
\text { (May-December }\end{array}$ & Soil & $\begin{array}{c}30.6 \% \\
(33 / 108)\end{array}$ & $\begin{array}{l}\text { Nested PCR on } 100 \\
\text { mg soil sample } \\
\text { Investigation } \\
\text { following two flood } \\
\text { hazards due to } \\
\text { typhoons Morakot } \\
\text { and Fanapi }\end{array}$ & Fuh et al., 2011 \\
\hline $\begin{array}{l}\text { Thailand } \\
\text { (Western } \\
\text { Part) }\end{array}$ & $\begin{array}{c}2016 \\
\text { (November) }\end{array}$ & Water and Soil & $\begin{array}{l}35.3 \% \\
(6 / 17)\end{array}$ & $\begin{array}{l}\text { Cultured in liquid } \\
\text { and solid EMJH } \\
\text { supplemented with } \\
100 \mu \mathrm{g} / \mathrm{ml} \text { of } 5- \\
\text { Fluoro-Uracil } \\
\text { followed by a rrs } \\
\text { nested PCR. } \\
\text { Water: } 0.5 \mathrm{~mL} \\
\text { filtered through } \\
0.22 \mu \mathrm{m} \text { from } 30 \\
\text { mL, cultured at } \\
28^{\circ} \mathrm{C} \\
\text { Soil: } 50 \mathrm{~g} \text {, } \\
\text { washings filtered } \\
\text { through } 0.22 \mu \mathrm{m} \\
\text { cultured at } 28^{\circ} \mathrm{C}\end{array}$ & $\begin{array}{c}\text { Chaiwattanarungruengpaisan } \\
\text { et al., } 2018\end{array}$ \\
\hline UK (London) & 1935 & $\begin{array}{l}\text { Slime from London } \\
\text { sewers }\end{array}$ & $\begin{array}{c}6.7 \\
(2 / 30)\end{array}$ & $\begin{array}{l}\text { Inoculation to } \\
\text { guinea pigs }\end{array}$ & Alston, 1935 \\
\hline $\begin{array}{l}\text { USA } \\
\text { (FL, Tampa) }\end{array}$ & $\begin{array}{c}2017 \\
\text { (December) }\end{array}$ & $\begin{array}{l}\text { Water } \\
\text { Soil }\end{array}$ & $\begin{array}{c}0.0 \% \\
(0 / 15) \\
\\
0.0 \% \\
(0 / 11)\end{array}$ & $\begin{array}{c}500 \mu \mathrm{l} \text { to } 30 \mathrm{ml} \text { of } \\
\text { water cultivated in } \\
\text { EMJH medium with } \\
5 \text {-fluoruracil }\end{array}$ & Stern et al., 2010 \\
\hline $\begin{array}{l}\text { USA } \\
\text { (IA) }\end{array}$ & $\begin{array}{c}1964 \\
\text { (August to } \\
\text { September) }\end{array}$ & $\begin{array}{l}\text { Big Creek water } \\
\text { Sampled with soil }\end{array}$ & $\begin{array}{l}30 \% \\
(1 / 3)\end{array}$ & $\begin{array}{c}\text { Inoculation to } \\
\text { guinea pigs } \\
5 \mathrm{ml} \text { Intraperitoneal } \\
\text { injection }\end{array}$ & Diesch and McCulloch, 1966 \\
\hline
\end{tabular}




\begin{tabular}{|c|c|c|c|c|c|}
\hline Area & Year & Sample Description & $\begin{array}{c}\text { Occurrence } \\
\text { Percent } \\
\text { Positive } \\
\text { (Sample } \\
\text { Numbers) }\end{array}$ & Detection Method & REF \\
\hline $\begin{array}{l}\text { USA } \\
\text { (CA, Long } \\
\text { Valley, Little } \\
\text { Hot Creek } \\
\text { Spring) }\end{array}$ & $\begin{array}{c}2015 \\
\text { (June) }\end{array}$ & Dendrolitic cone & $\begin{array}{c}100 \% \\
(1 / 1)\end{array}$ & $\begin{array}{c}\text { 16S metagenomic } \\
\text { sequencing } \\
\text { (Illumina MiSeq } \\
\text { platform) } \\
\text { V4 region of the } \\
16 \mathrm{~S} \text { rRNA gene } \\
\text { (positions } 519 \text { to } \\
\text { 802, Escherichia } \\
\text { coli numbering). } \\
\text { Dendrolitic cones } \\
\text { ranged in height } \\
\text { from } 0.5-2.0 \mathrm{~cm}\end{array}$ & Bradley et al., 2017 \\
\hline
\end{tabular}

${ }^{\mathrm{a}}$ NR: Not Reported; ${ }^{\mathrm{b}}$ Isolated from blood cultures of moribund animals

Table 5. Pathogenic Leptospira occurrence in drinking water samples

\begin{tabular}{|c|c|c|c|c|c|}
\hline Area & Year & Sample Description & $\begin{array}{c}\text { Occurrence } \\
\text { Percent Positive } \\
\text { (Sample Numbers) }\end{array}$ & Detection Method & References \\
\hline $\begin{array}{l}\text { Chile } \\
\text { (Los Rios) }\end{array}$ & $\begin{array}{l}2010 \text { to } \\
2012 \\
\text { (November } \\
\text { to April) }\end{array}$ & Animal drinking water ${ }^{a}$ & $\begin{array}{c}14.5 \% \\
(12 / 83)\end{array}$ & $\begin{array}{l}\text { lipL32-PCR on } \\
50 \mathrm{~mL} \text { to } 1.0 \mathrm{~L} \text { water }\end{array}$ & $\begin{array}{c}\text { Muñoz-Zanzi et al., } \\
2014\end{array}$ \\
\hline $\begin{array}{l}\text { Chile } \\
\text { (Los Rios) }\end{array}$ & $\begin{array}{l}2010 \text { to } \\
2012 \\
\text { (November } \\
\text { to April) }\end{array}$ & Human drinking sources & $\begin{array}{l}19.1 \% \\
(9 / 47)\end{array}$ & $\begin{array}{c}\text { lipL32-PCR on } \\
50 \mathrm{~mL} \text { to } 1.0 \mathrm{~L} \text { water }\end{array}$ & $\begin{array}{c}\text { Muñoz-Zanzi et al., } \\
2014\end{array}$ \\
\hline $\begin{array}{l}\text { Chile } \\
\text { (Los Rios) }\end{array}$ & $\begin{array}{l}2010 \text { to } \\
2012 \\
\text { (October to } \\
\text { April) }\end{array}$ & Animal drinking water ${ }^{a}$ & $\begin{array}{c}16.5 \% \\
(14 / 85)\end{array}$ & $\begin{array}{c}\text { PCR and } \\
\text { sequencing on } 50 \\
\text { mL to } 1 \mathrm{~L} \text { water }\end{array}$ & Mason et al., 2016 \\
\hline $\begin{array}{l}\text { Chile } \\
\text { (Los Rios) }\end{array}$ & $\begin{array}{l}2010 \text { to } \\
2012 \\
\text { (October to } \\
\text { April) }\end{array}$ & Human drinking sources & $\begin{array}{c}14.7 \% \\
(14 / 95)\end{array}$ & $\begin{array}{c}\text { PCR and } \\
\text { sequencing on } 50 \\
\text { mL to } 1 \mathrm{~L} \text { water }\end{array}$ & Mason et al., 2016 \\
\hline $\begin{array}{l}\text { China } \\
\text { (Nanjing, } \\
\text { Bejhekou } \\
\text { drinking } \\
\text { water } \\
\text { plant) }\end{array}$ & $\mathrm{NA}^{\mathrm{b}}$ & Drinking Water & $\begin{array}{c}0.45 \% \text { of total } \\
\text { metagenomic reads }\end{array}$ & $\begin{array}{l}\text { Metagenomics ( } 454 \\
\text { pyrosequencing) } \\
\text { L. interrogans still } \\
\text { in tap water after } \\
\text { chlorination }\end{array}$ & Huang et al., 2014 \\
\hline $\begin{array}{l}\text { Colombia } \\
\text { (Cordoba) }\end{array}$ & $\begin{array}{c}2009 \text { to } \\
2011\end{array}$ & Animal drinking water ${ }^{a}$ & $\begin{array}{l}5.56 \% \\
(1 / 18)\end{array}$ & $\begin{array}{c}\text { Culture enrichment } \\
0.5 \mathrm{~mL} \text { with and } \\
\text { without filtration } \\
\text { through } 0.45 \mu \mathrm{m} \\
\text { filter }\end{array}$ & $\begin{array}{l}\text { Calderon et al., } \\
2014\end{array}$ \\
\hline
\end{tabular}




\begin{tabular}{|c|c|c|c|c|c|}
\hline Area & Year & Sample Description & $\begin{array}{c}\text { Occurrence } \\
\text { Percent Positive } \\
\text { (Sample Numbers) }\end{array}$ & Detection Method & References \\
\hline $\begin{array}{l}\text { Colombia } \\
\text { (Cordoba) }\end{array}$ & NA & Drinking Water & $\begin{array}{c}0 \% \\
(0 / 13)\end{array}$ & $\begin{array}{c}15 \mathrm{~mL} \text { water } \\
\text { samples collected } \\
\text { on farms } \\
\text { Centrifuged 14,000 } \\
\text { rpm / } 5 \text { min. Pellet } \\
\text { washed by PBS. } \\
\text { PCR and } \\
\text { sequencing. }\end{array}$ & $\begin{array}{l}\text { Ensuncho-Hoyos et } \\
\text { al., } 2017\end{array}$ \\
\hline $\begin{array}{l}\text { Thailand } \\
\text { (Bangkok) }\end{array}$ & $\begin{array}{c}2011 \\
\text { (November) }\end{array}$ & Tap Water & $\begin{array}{c}0 \% \\
(0 / 11)\end{array}$ & $\begin{array}{c}1.5-6 \mathrm{~L} \\
\text { qPCR } \\
\text { Bacteria collected } \\
\text { on } 0.2 \mu \mathrm{m} \text { filter } \\
\text { membrane }\end{array}$ & $\begin{array}{c}\text { Chaturongkasumrit } \\
\text { et al., } 2013\end{array}$ \\
\hline $\begin{array}{l}\text { Thailand } \\
\text { (Bangkok) }\end{array}$ & $\begin{array}{c}2011 \\
\text { (November) }\end{array}$ & Filtered Tap Water & $\begin{array}{c}0 \% \\
(0 / 5)\end{array}$ & $\begin{array}{c}1.5-6 \mathrm{~L} \\
\text { qPCR } \\
\text { Bacteria collected } \\
\text { on } 0.2 \mu \mathrm{m} \text { filter } \\
\text { membrane }\end{array}$ & $\begin{array}{c}\text { Chaturongkasumrit } \\
\text { et al., } 2013\end{array}$ \\
\hline
\end{tabular}

${ }^{a}$ Non-potable drinking water for animals; ${ }^{b}$ NA: Not Available

\subsection{Detection Methods}

Leptospires might be detected by either culture and isolation or using molecular techniques like (quantitative) PCR. Leptospira spp. are fastidious slow-growing organisms with very specific nutritional requirements. However, as for most bacterial species, initial work used classical, culturebased isolation procedures. Although several different culture media have been developed and used for Leptospira, most studies have used the oleic acid - albumin culture medium Ellinghausen-McCullough-Johnson-Harris $(\mathrm{EMJH})$ or the rabbit serum-enriched Korthof's enrichments; as liquid or semi-solid media for at least initial culture, thus preventing quantification. Since the mid 1960s, the control of contaminants has been achieved by including 5-Fluoro-Uracil into the culture medium (Johnson and Rogers, 1964). More recently, a combination of selective antimicrobial agents as proposed by Chakraborty et al. (2011) has increasingly been used (sulfamethoxazole, $40 \mu \mathrm{g} / \mathrm{mL}$; trimethoprim, $20 \mu \mathrm{g} / \mathrm{mL}$; amphotericin B, 5 $\mu \mathrm{g} / \mathrm{mL}$; fosfomycin, $400 \mu \mathrm{g} / \mathrm{mL}$; and 5-fluorouracil, 100 $\mu \mathrm{g} / \mathrm{mL}$ ). Whether these culture media and selective agents favor the growth of all Leptospira species and strains is still unknown, and the isolation process most likely results in the loss of Leptospira diversity. In addition, although viable but non-culturable (VBNC) Leptospira have not been reported, the ability of different strains to grow in vitro in culture media is still very poorly established.

As with any culture-based isolation technique, fast-growing saprophytic species are most frequently isolated and may jeopardize the detection and isolation of slower-growing virulent leptospires. Historically, to gain insight into pathogenic Leptospira from waters and soils, direct inoculation of environmental samples into susceptible animal models have been used. Pathogenic leptospires that induce infection and disease in such test animals and cultures from their blood or target organs allows for the recovery of pure cultures. Examples are provided in the following section 2.2, pathogenic leptospires were isolated from recreational waters in the USA after inoculation into guinea pigs (Diesch and McCulloch, 1966).

A number of pathogenic leptospires were similarly recovered from soils and waters in Malaysia after inoculation of hamsters (Baker and Baker, 1970). This technique used many susceptible animals (hamsters or guinea pigs), and is currently unacceptable from an ethical perspective. Of note, this technique does not allow a quantitative assessment, since the pathogenic leptospires are amplified or lost in the test animals by immune clearance, depending both on their own virulence and their initial concentration in the sample studied (minimal infective dose). Animals might also die from another infection that may mask a virulent leptospire. To summarize, this technique has an excellent specificity if Leptospira isolation is successful, but may suffer from a low sensitivity presumably leading to a number of false negative results. Consequently, the proportion of positive samples observed with this animal-enrichment technique are expected to underestimate the true occurrence.

Once the leptospires are isolated, there is no easy and specific phenotypic technique for their identification, even at the species level. This further complicated the early studies of Leptospira in the environment, but modern molecular methods are now reducing this problem. The International Leptospirosis Society regularly produces a position statement on the speciation of Leptospiral isolates, which is publicly available (https://leptosociety.org/resources). The most recent recommendation is to use Whole Genome Sequencing 
techniques and genomic comparisons for speciation.

\subsubsection{Culture from environmental samples}

There is no standard protocol for culturing virulent species of Leptospira from bodies of fresh water or soil. Furthermore, there are only a few reports describing the isolation of virulent Leptospira from environmental samples; as discussed above, the main difficulty in the isolation of these species is the overgrowth of environmental bacteria or the fast-growing saprophytic Leptospira (Barragan et al., 2011; Benacer et al., 2013; Saito et al., 2013). Culture-based protocols include the use EMJH (Ellinghausen and McCullough modified by Johnson and Harris) culture medium containing cocktails of antibacterial and anti-fungal compounds such as sulfamethoxazole, trimethoprim, amphotericin B, fosfomycin, and 5-fluorouracil (Benacer et al., 2013; Saito et al., 2015; Saito et al., 2013). Alternatively bacterial contamination in water samples can be reduced by utilizing $0.22 \mu \mathrm{m}$ filtrate before enriching in EMJH medium, then isolating colonies on solid medium (Saito et al., 2015; Wuthiekanun et al., 2013).

2.1.2 Moleular based methods: amplification of leptospiral DNA from environmental samples

Due to difficulties in culturing Leptospira from environmental samples, numerous PCR-based techniques have been developed that mainly target genes only present in pathogenic Leptospira, such as lipL32 (Muñoz-Zanzi et al., 2014; Vinod Kumar et al., 2016b; Aviat et al., 2010) or pathogenic specific sequences of genes, such as flaB (Villanueva et al., 2014), secY (Perez and Goarant, 2010; Guernier et al., 2018) and the 16S rRNA gene (Ganoza et al., 2006). Because of sequence polymorphisms, PCR targeting lipL32 or secY fail to detect virulent Leptospira of the intermediate cluster (e.g. L. fainei, L. broomii, L. inadai, $L$ wolffii, L. licerasiae), which are commonly found in water (Ganoza et al., 2006, Thaipadungpanit et al., 2013).

A second problem with PCR methods used to date is that detection of genomic DNA sequences provides no indication of the viability of bacteria in water or other matrices. In addition to the possible use of PMA or EMA to reduce cell membrane compromised or free DNA detections (Thibeaux et al., 2017; Soupé-Gilbert et al., 2017), targeting pre-RNA appears to be an alternative with possibly greater precision in detecting viable bacteria (Cangelosi, 2009; Gedalanga and Olson, 2009). While yet to be reported for Leptospira, targeting pre-RNA before and after media stimulation and assaying by qRT-PCR to identify differences in the preRNA copies present should correspond to viable Leptospira (Cangelosi, 2018).

Most recently, detailed procedures for the molecular detection of pathogenic leptospires have been published, which will probably trigger further studies on leptospires in the environment (Beigel and Verma, 2017; Riediger et al., 2016; Thibeaux et al., 2018a). There has also been increased use of high throughput sequencing technologies. For example, 16S rRNA amplicon sequencing yielded evidence of the presence of Leptospira in various water sources (Huang et al., 2014; Zhang et al., 2017; EscobedoHinojosa and Pardo-Lopez, 2017). Studies using such socalled next generation DNA sequencing approaches will likely provide improved information on Leptospira ecology in the coming years.

\subsection{Data on Occurrence}

\subsubsection{Excreta in the environment}

Pathogenic Leptospira live and multiply in the proximal kidney tubules of reservoir animals, which are frequently asymptomatic, and are then shed through the urine. Thus, they reach soils and waters in the environment, which are the sources of most human infection. However, very little is known on the actual numbers of leptospires that are shed by reservoir animals. A detailed analysis of the kinetics of excretion in mice shows that excretion increases with age, reaching $3.0 \times 10^{7} / \mathrm{ml}$ of urine and suggesting that older rodents excrete larger amounts of leptospires (SoupéGilbert et al., 2017). A meta-analysis indicated that reservoir rats excrete the greatest concentration of leptospires (5.7x $10^{6}$ per $\mathrm{mL}$ of urine), but large mammals produce the greatest quantities (up to $10^{9}$ leptospires per day) because of the larger volume of urine (Barragan et al., 2017). This meta-analysis suggested that humans could shed approximately $10^{6}$ leptospires per day. However, except in very specific situations, humans usually do not become chronic carriers and only excrete leptospires for a couple of days to weeks (Levett, 2001). Therefore, human excreta are usually not considered to play an epidemiological role in transmission of leptospirosis.

\subsubsection{Sewage}

Leptospirosis has been historically associated with sewage and is still an occupational hazard in sewerworkers. Pathogenic leptospires were isolated from sewage or sewage slime very early (Alston, 1935; Coghlan and Kmety, 1987; Jones et al., 1981). Using molecular techniques, pathogenic leptospires were evidenced from sewage in the Peruvian Amazon (Ganoza et al., 2006) and from a wastewater sample in Colombia (Ensuncho-Hoyos et al., 2017). In Brazilian slums, open sewers are considered as a major source of human leptospirosis, yet may be more a function of rat urine presence than human sewage. A recent study in an urban slum in Salvador, Brazil, demonstrated the presence of pathogenic leptospires in more than one third of sewage water samples, with a concentration that range $2.0 \times 10^{3}$ to $1.7 \times 10^{6} / 100 \mathrm{~mL}$. The highest concentration were reported during the rainy season and at sampling sites nearest the bottom of the valley and thus most vulnerable to flood waters (CasanovasMassana et al., 2018).

\subsubsection{Manure}

Due to the huge quantities of leptospires potentially excreted in the urine by large mammals, manure can be a major source of contamination. Direct detection in or isolation of pathogenic leptospires from manure is a major 
challenge, because of the enormous bacterial burden and the difficulties of selectively growing leptospires, as well as the major concern of PCR inhibitors preventing a relevant use of molecular detection. Cattle manure was shown to be a source of pathogenic leptospires in field conditions (Gillespie and Ryno, 1963). A study that modeled the shedding of leptospires in cattle manure found they were resilient in an oxidation ditch designed for nutrient removal, persisting for upwards of two months (Diesch, 1971). More recently, a change in the management of livestock manure in Korea was associated with a significant decrease in leptospirosis incidence (Ryu et al., 2017).

\subsubsection{Surface waters}

As described above (see section 2.1), studies using only culture-based methods mostly detected saprophytic leptospires, which are normal inhabitants of water and soils and frequently overgrow virulent leptospires in culture. Using inoculation to susceptible animals (guinea pigs or hamsters), pathogenic leptospires have been isolated from both temperate and tropical surface waters (Diesch and McCulloch, 1966; Crawford Jr et al., 1969; Baker and Baker, 1970; Alexander et al., 1975; Jackson et al., 1993). Molecular detection has been used since the late 1990s and notably allowed some DNA from pathogenic Leptospira to be detected from lake water associated with a recreational outbreak of leptospirosis after a triathlon in Illinois, USA (Morgan et al., 2002). Later molecular methods detected pathogenic leptospires from $23 \%$ of various surface water sources in Thailand (Tansuphasiri et al., 2006). Of note, classical PCR cannot provide direct quantitative information about the leptospires, but both studies cited above suggest low concentrations.

The use of quantitative real time PCR (qPCR) does enable direct quantitative estimates of concentrations of leptospires in water sources. Concentrations in the range one to seventeen thousand leptospires per $\mathrm{mL}$ (including both pathogenic and intermediate strains) were measured in various surface water sources in Peru, notably showing both higher frequency and higher concentrations in urban (especially in a market area) than in rural area (Ganoza et al., 2006). In Hawaiian streams, Leptospira were detected in 87 of 88 water samples $(98.8 \%)$, with concentrations from 5 to $10^{4}$ genomes / $100 \mathrm{~mL}$ (approx. 1 to $2.0 \times 10^{3}$ leptospires ( $100 \mathrm{~mL}$ ), with a strong correlation with turbidity. Further sequencing of the PCR product evidenced only species from the intermediate cluster (Viau et al., 2011). In a temperate environment near Lyon, France, pathogenic Leptospira were detected in 3 of 47 (6.38\%) water samples collected from ponds with concentrations in the range $10^{5}$ to $10^{6} / 100 \mathrm{~mL}$ (Vein et al., 2012). In the temperate region of Los Rios in South-Central Chile, pathogenic leptospires evidenced by PCR were more common in standing waters $(19.3 \%$ of puddles and $45.5 \%$ of open containers) than in running waters $(3.9 \%$ in canals or rivers). The overall detection rate was 77 out of 570 (13.5\%) water samples, revealing the ubiquity of pathogenic Leptospira in surface waters in this temperate region (Muñoz-Zanzi et al., 2014).

Particular attention should be paid to floodwaters, which are known to be responsible for numerous leptospirosis infections and outbreaks in humans. Although floodwaters have rarely been studied (Thaipadungpanit et al., 2013; Chaturongkasumrit et al., 2013), they should be considered as periods of increased leptospirosis risk, as shown by the high numbers of leptospirosis outbreaks triggered by floods (Smith et al., 2013; Park et al., 2006; Matono et al., 2015; Gaynor et al., 2007; Easton, 1999) (Table 2-5).

\subsubsection{Groundwater}

Few studies have investigated leptospires in ground water. Recent 16S rRNA gene amplicon studies confirm a greater abundance of Leptospira in surface than in underground waters (Delafont et al., 2016). Pathogenic Leptospira were reported from underground water sources in Thailand, but the study did not provide hydrologic details about the water sources investigated (Kurilung et al., 2017).

\subsubsection{Drinking water}

Leptospira have been detected in drinking water samples in several studies. Saprophytic leptospires are normal inhabitants of freshwater, which do not involve any sanitary risk. However, there has also been evidence of pathogenic leptospires from drinking water for animals (Calderon et al., 2014; Muñoz-Zanzi et al., 2014; Mason et al., 2016; Kurilung et al., 2017), but also for humans (Muñoz-Zanzi et al., 2014; Mason et al., 2016). Very interestingly, a shotgun metagenomics study retrieved a Leptospira spp. draft genome from chlorinated drinking water, suggesting an ability to resist some degree of chlorination (Zhang et al., 2017). Similarly, a 16S rRNA gene amplicon study found Leptospira spp. sequence reads in a drinking water network, both right after chlorination (initial concentration of $0.6-0.8 \mathrm{mg} / \mathrm{L}$ free chlorine) and in final tapwater ( $0.1 \mathrm{mg} / \mathrm{L}$ residual chlorine); in this study, a higher relative abundance of Leptospira spp. sequence reads in tap water compared to initial water further supports the hypothesis of resistance to chlorination (Huang et al., 2014). Whether this resistance is related to Leptospira ability to form biofilms (discussed above in section 2) remains to be determined.

\subsubsection{Seawater}

Leptospires are thought to survive poorly in seawater. However, there is limited evidence of some degree of saltwater tolerance by some Leptospira strains. One study reported the isolation of a virulent leptospire that was apparently tolerant to seawater (Grune Loffler et al., 2015). Another study, using 16S rRNA gene amplicon, reported Leptospira in marine waters and soils in the Gulf of Mexico (Escobedo-Hinojosa and Pardo-Lopez, 2017). On the other hand, leptospirosis cases observed in marine mammals could be due to coastal contamination by virulent leptospires arising from terrestrial runoff and contamination of coastal marine environments (Bogomolni et al., 2008; Cameron et al., 2008; Prager et al., 2013). 


\subsubsection{Sludge}

Leptospires have been reported from sewage and sewage sludge since the 1930s (Alston, 1935; Jones et al., 1981; Coghlan and Kmety, 1987), yet there has been little interest generally in such reports because human sewage does not appear to be a significant source of human disease.

\subsubsection{Soil}

Noguchi (1918) appears to be one of the first to report soils as a possible environment where Leptospira survive. However, because of the technical challenges of studying delicate slow-growing organisms in soils, this environmental compartment has been poorly studied.

Using animal inoculation, pathogenic Leptospira were recovered from Malaysian soil washings in the early 1960s. The authors noted a higher isolation frequency from soil washings than from waters (Baker and Baker, 1970). Quite similarly, a study in Minnesota, which failed to isolate virulent strains, noted that isolation of leptospires was more frequent from soils than from adjacent waters (Henry and Johnson, 1978). Similarly in Hawaii, leptospires were isolated from 7 of 13 water samples, but from all 16 soil samples examined (Wilson and Fujioka, 1995). In New Caledonia where leptospirosis is endemic, a source tracking study used viability-PCR and detected viable pathogenic leptospires in river soils weeks after the contamination events (Thibeaux et al., 2017). A combination of selective agents was proven to be very effective for the culture and isolation of Leptospira from environmental samples (Chakraborty et al., 2011). Using this selection techniques, a great biodiversity of leptospires were isolated from tropical soils in New Caledonia, supporting the hypothesis that soils may be the original habitat of the genus Leptospira and a possible environmental reservoir of pathogenic strains (Thibeaux et al., 2018b; Thibeaux et al., 2018a). This hypothesis is also supported by other findings, notably the positive correlation between Leptospira concentration and turbidity (Viau and Boehm, 2011) or the role of floods in triggering leptospirosis outbreaks, as presented above.

\subsubsection{Irrigation water and on crops}

Irrigation waters are mostly surface waters, though groundwater is sometimes used. Most of the risks associated with irrigation waters should be evaluated by knowledge acquired from the water source considered and described in the corresponding section. Very few studies have considered Leptospira irrigation water.

There is both direct and indirect evidence of a high risk of leptospirosis in humans that rely on irrigated crops. In Korea, pathogenic leptospires were isolated from the water of a rice paddy field identified as a source of a leptospirosis outbreak (Kim, 1987), providing direct evidence. Indirect evidence relies on the epidemiological association of human leptospirosis with activity in rice paddy fields (Kim, 1987; Ryu and Liu, 1966; Ivanova et al., 2012), but also other irrigated crops, such as irrigated taro fields (Massenet et al., 2015).

Crops are not considered to represent a direct risk for leptospirosis, but improper storage can lead to rodent population growth, constituting an indirect risk of leptospirosis via increased excretion of urine.

\subsubsection{Fish and shellfish}

Leptospira isolates have historically been recovered from a number of cold-blooded animals, notably amphibians and reptiles (Andrews et al., 1965; Minette, 1983). More recently, molecular detection suggested Leptospira carriage in the kidneys of some reptiles (Jobbins and Alexander, 2015). Positive serology was sometimes reported from freshwater fishes (Mgode et al., 2015), but this finding is considered anecdotal and does not mean that the seropositive fishes had the ability to chronically carry and shed live virulent leptospires. Current scientific consensus is that cold-blooded vertebrates and invertebrates are not involved as reservoirs of humanpathogenic leptospires, and they have not been reported as possible vehicles of human contaminations. On the other hand, freshwater fish farming might pose an occupational risk for leptospirosis, through extensive and prolonged contact with freshwater, as well as through the possible presence of rodents at feed stock facilities.

\subsubsection{Air}

Leptospirosis is not an airborne infection and is only exceptionally acquired through the respiratory system. Aerosols from infectious sources (contaminated water sources, mammal urines, urine-humid beds of rodents in animal facilities) can occasionally induce leptospirosis through the mucous membranes of the respiratory tract (WHO, 1999; Levett, 2001). Leptospires were isolated from an air-conditioning plant in New Zealand however, the strains isolated did not demonstrate virulence in susceptible animal models, suggesting that they were not pathogenic leptospires (Ris and Hamel, 1979).

\subsection{Persistence}

Environmental survival and persistence of virulent Leptospira was recognized very early on as key to leptospirosis epidemiology (Noguchi, 1918). Virulent leptospires are thought to multiply in animal hosts and only survive in the environment. However, because of the technical difficulties involved in culturing and identifying Leptospira in complex environmental samples, limited information on environmental Leptospira survival has been published. Most studies have used microcosms in laboratory experiments to study the survival of pathogenic leptospires under different physico-chemical conditions.

In general, limited quantitative data was identified for Leptospira persistence or survival in excreta or environmental matrices. Nonetheless, factors likely to increase persistence include coaggregation with different bacteria within biofilms (Vinod Kumar et al., 2015b). Hence, pathogenic Leptospira may persist for months in surface waters (Barragan et al., 2011). 
One century ago, Noguchi (1918) initially demonstrated both the survival and virulence of pathogenic leptospires for up to one week in drinking water. Later in a more complex experimental design, the influence of temperature and $\mathrm{pH}$ were studied, showing a longer survival at neutral to slightly alkaline $\mathrm{pH}$ and an optimal temperature around $25-27^{\circ} \mathrm{C}$, with temperatures above $60^{\circ} \mathrm{C}$ killing leptospires in a few seconds (Chang et al., 1948). This same study showed survival of 100 days with the addition of $1 \%$ horse serum in sterile tap water. Based on inoculation studies using susceptible animal hosts, the survival and infectivity was found to be maintained in soils for more than 40 days (Smith and Self, 1955). Such evidence, as well that from other as other studies, has built the case that leptospires can survive and remain infective for weeks to months in a favorable environment. However, it must also be noted that bacterial survival is not only environment-dependent, but also strain-dependent and different pathogenic Leptospira strains have shown different survival capabilities under the same environmental conditions (Smith and Turner, 1961).
The longest survival reported in nutrient-deprived conditions was reported from an experiment in a mineral bottled water held at $30^{\circ} \mathrm{C}$, where a Leptospira interrogans serogroup Icterohaemorrhagiae survived and even induced a lethal disease in gerbils after 593 days (Andre-Fontaine et al., 2015).

In natural environments, the isolation of an identical strain five months apart in the same rain puddle suggested its ability to survive in wet soil between rain events (Saito et al., 2013). Similarly, using viability-PCR and genotyping, the Leptospira interrogans strain involved in human infections was shown to persist in soils from river edges and sediments where human infections had occurred 9 weeks earlier (Thibeaux et al., 2017). Although repeat contamination of natural areas is possible, there is strong evidence that pathogenic Leptospira not only survive, but also remain infective for weeks to months in wet soils and freshwater ecosystems.

Table 6 shows early studies done on persistence more recent data are not available.

Table 6. Persistence of Leptospira in different matrices

\begin{tabular}{|c|c|c|c|c|}
\hline Area (Year) & $\begin{array}{l}\text { Starting Concentrations } \\
\text { (Species) }\end{array}$ & $\begin{array}{c}\text { Matrix/ } \\
\text { Conditions } \\
\text { Temperature }\left({ }^{\circ} \mathrm{C}\right)\end{array}$ & Maximum Survival in Days & Reference \\
\hline $\begin{array}{l}\text { New York } \\
(1918)\end{array}$ & $\begin{array}{c}\text { Unknown } \\
\text { (L. interrogans serogroup } \\
\text { Icterohaemorrhagiae) }\end{array}$ & East river water & $<1$ & $\begin{array}{l}\text { Noguchi, } \\
1918\end{array}$ \\
\hline $\begin{array}{l}\text { New York } \\
(1918)\end{array}$ & $\begin{array}{c}\text { Unknown } \\
\text { (L. interrogans serogroup } \\
\text { Icterohaemorrhagiae) }\end{array}$ & sewage water & $<1$ & $\begin{array}{l}\text { Noguchi, } \\
1918\end{array}$ \\
\hline $\begin{array}{l}\text { New York } \\
(1918)\end{array}$ & $\begin{array}{c}\text { Unknown } \\
\text { (L. interrogans serogroup } \\
\text { Icterohaemorrhagiae) }\end{array}$ & stagnant water & $<1$ & $\begin{array}{l}\text { Noguchi, } \\
1918\end{array}$ \\
\hline $\begin{array}{l}\text { New York } \\
(1918)\end{array}$ & $\begin{array}{c}\text { Unknown } \\
\text { (L. interrogans serogroup } \\
\text { Icterohaemorrhagiae) }\end{array}$ & $\begin{array}{l}\text { horse stool } \\
\text { emulsion }\end{array}$ & $<1$ & $\begin{array}{l}\text { Noguchi, } \\
1918\end{array}$ \\
\hline $\begin{array}{l}\text { New York } \\
(1918)\end{array}$ & $\begin{array}{c}\text { Unknown } \\
\text { (L. interrogans serogroup } \\
\text { Icterohaemorrhagiae) }\end{array}$ & sewer filtrate & $<1$ & $\begin{array}{l}\text { Noguchi, } \\
1918\end{array}$ \\
\hline $\begin{array}{l}\text { New York } \\
(1918)\end{array}$ & $\begin{array}{l}\text { (Pathogenic Leptospira } \\
\text { strain Flanders) }\end{array}$ & $\begin{array}{l}\text { non sterile distilled } \\
\text { water with few } \\
\text { large motile bacilli }\end{array}$ & 3 & $\begin{array}{l}\text { Noguchi, } \\
1918\end{array}$ \\
\hline $\begin{array}{l}\text { New York } \\
(1918)\end{array}$ & $\begin{array}{l}\text { (Pathogenic Leptospira } \\
\text { strain Flanders) }\end{array}$ & drinking water & 7 & $\begin{array}{c}\text { Noguchi, } \\
1918\end{array}$ \\
\hline $\begin{array}{l}\text { North } \\
\text { Queensland, } \\
\text { Brisbane, } \\
\text { Australia } \\
\text { (1950s) }\end{array}$ & $\begin{array}{c}20 \mathrm{~mL} \text { of a } 7 \text { day culture } \\
\text { into soil } \\
\text { Pathogenic Leptospira } \\
\text { (strain Australis A) }\end{array}$ & Soil & $\begin{array}{l}43 \text { days in soil } \\
3 \text { days in water }\end{array}$ & $\begin{array}{l}\text { Smith and } \\
\text { Self, } 1955\end{array}$ \\
\hline $\begin{array}{l}\text { North } \\
\text { Queensland, } \\
\text { Brisbane, } \\
\text { Australia } \\
\text { (1950s) }\end{array}$ & $\begin{array}{c}20 \mathrm{~mL} \text { of a } 7 \text { day culture } \\
\text { into soil } \\
\text { Pathogenic Leptospira } \\
\text { (strain Australis A) }\end{array}$ & $\begin{array}{c}\text { Rain water from } \\
\text { soil }\end{array}$ & $\begin{array}{l}15 \text { days in soil } \\
4 \text { days in water }\end{array}$ & $\begin{array}{l}\text { Smith and } \\
\text { Self, } 1955\end{array}$ \\
\hline
\end{tabular}




\subsection{Reductions by Sanitation Management}

Very limited data exists on the specific removal efficiencies of leptospires via sanitation management and traditional wastewater treatment processes. Nonetheless, general disinfection methods and physical removal techniques would be considered necessary for the control of Leptospirosis. Adequate surrogates for Leptospira removal in engineered systems have not been identified, but traditional fecal indicators (i.e., Escherichia coli and Enterococci) have recently been used to assess environmental risk during a leptospirosis outbreak in Israel (Dadon et al., 2018). Sports events in apparently pristine surface waters have been frequently linked to leptospirosis outbreaks (Sejvar et al., 2003), suggesting that coliforms and $E$. coli counts may not be a good indicator of leptospiral risk (Morgan et al., 2002). Therefore, whether they may be reasonable substitutes for evaluating removal techniques remains to be determined. Campylobacter spp. could also serve as a surrogate due to it also being a Gram-negative bacterium with a similarly thin and elongated physiology. Leptospira is generally considered to be an environmentally-associated pathogen where human infection is strongly linked to flooding events or outside contamination of surface waters from animal urine. Outbreaks of leptospirosis generally do not occur in regions with proper sanitation practices and may be a reason for the lack of data in engineered systems. What published data is available on Leptospira in sanitation and related systems is summarized in the following subsections.

Overall, effective rodent control and urine management from various domesticated animals are important aspects in managing leptospires associated with sanitation systems.

Recommendations for a person in a developing region to manage Leptospira include:

1. Use chlorine tablets to treat drinking water. If no chlorine is available, heat the water past $50^{\circ} \mathrm{C}$ for at least one minute.

2. Do not bathe in, or use recreationally, surface waters after flooding events or with known sources of fecal contamination. This is especially regarding individuals with open cuts or sores.

3. Compost manure/digestate if you plan on applying it to land or otherwise (see below section 3.1).

4. Prevent livestock excrement from surfaces waters, outbreaks are traced to animal feces and urine in frequently used waters.

5. Control pests like rats, mice, and other rodents by improving food storage and garbage disposal conditions.

\subsection{Wastewater Treatment}

\subsubsection{On-site waterless sanitation}

The reduction of Leptospira spp. being introduced into the environment, originating from either human or animal, would help in reducing the frequency of human contact with pathogenic serotypes. Over a third of the world does not have access to adequate sanitation facilities (WHO, 2006), and open defecation is still a common practice in some of these regions. Because of the direct link between flooding events and outbreaks of Leptospirosis, there is further emphasis made on the physical containment of unabated excreta from entering the environment. During the rainy season, these uncontained wastes allow runoff into surface waters where they collect and allow for transmission to humans downstream. The implementation of basic sanitation infrastructures can vastly aid in the overall reduction and prevention of waterborne pathogenic Leptospira transmission.

\subsubsection{Pit Latrines, vault toilets, dry toilets}

The application of basic types of toilets or pit latrines to create physical separation between waste streams and humans would be considered best practice for hygiene and sanitation management of leptospires. The pathogen content of urine is much less than in feces (Höglund et al., 2002), suggesting the prioritization of solids partitioning of human waste if at all else.

\subsubsection{Composting}

Composting is considered an effective, passive, waterless approach to reducing the overall biological activity and concentration of pathogenic bacteria in highly concentrated wastes and has been found to be effective in reducing pathogenic Leptospira. The main factors influencing the inactivation of Leptospira spp. in sludge and manure composting are the temperature and $\mathrm{pH}$ characteristics of the compost. Parker and Walker (2011) simulated the $\mathrm{pH}$ and temperature profiles traditionally occurring during composting, evaluating their effect on the survivability of the pathogenic leptospires. Via logistic regression, they concluded that a temperature profile above $45^{\circ} \mathrm{C}$ for at least 4 hours has the potential to kill leptospires. Thermophilic temperatures $>50^{\circ} \mathrm{C}$ for composting would then have the potential to kill leptospires in a few seconds, given that the entirety of the waste is subjected to comparable temperatures (Chang et al., 1948; Parker and Walker, 2011). Leptospires have a slight favorability towards alkaline $\mathrm{pH}$ profiles (Smith and Turner, 1961), but in regards to the heterogeneity of compost matrices, the $\mathrm{pH}$ dependency of Leptospira survivability seems to dissolve (Parker and Walker, 2011). Composting would be considered a viable and effective solution for the management of leptospires in manure.

\subsubsection{Oxidation ditch}

Diesch (1971) performed a study simulating an oxidation ditch being fed cattle manure from infected animals at a 1:10 scale laboratory model as well as field sampling. Leptospires were identified via dark-field microscopy in the aerated portion of the ditch for $>60$ days during summer temperature profiles as compared to 5 days in the anaerobic portion of the sludge. This suggests that available dissolved oxygen is critical to the survival of leptospires in comparable matrices. The study ended before a final contact time could be established for the complete 
removal of leptospires from the aerated portion.

\subsubsection{Waste stabilization ponds}

Lined or unlined waste ponds are used worldwide to passively treat wastewater streams. Depending on the climate of the region, the effluents of these stabilization ponds can vary greatly, with a preference for warmer weather that allows for higher kinetic removal rates (Hickey et al., 1989). Although specific reductions in Leptospira concentrations in waste stabilization ponds have not been documented, it can be inferred that the level of dissolved oxygen in these ponds would dictate the efficacy of Leptospira reduction. Being that this a passive technique (no mechanical mixing or aeration), the dissolved oxygen content would be minimized in the lower portions of the stratified pond where a reduction of active leptospires would be anticipated.

\subsubsection{Wetlands}

Wetlands or "constructed wetlands" are artificial environments used to treat either municipal or industrial wastewaters. These systems are designed for the passive reduction of nutrient loadings on the environment by mechanisms already present in a natural ecosystem (nitrification, denitrification, phosphorus removal). These systems are not designed nor intended for pathogen removal and would not be considered a viable alternative. The persistence of leptospires in wet and aerated soils and sediments is well documented.

\subsubsection{Aerated lagoons}

No reports of Leptospira spp. reductions by aerated lagoons were identified.

\subsubsection{Wastewater treatment facilities}

\subsubsection{Primary/preliminary treatment}

No reports of Leptospira spp. reductions by primary/preliminary treatment were identified.

\subsubsection{Activated sludge}

Morphological spirochetes have been found in the activated sludge of treatment facilities in Amsterdam, but specific structural markers of the Leptospira genus were not found (Deinema, 1976). Concentrated levels of spirochetes were seen in the interior of aggregated flocs and as motile cells on the floc surfaces. Being that Leptospira is an aerobic and chemoheterotrophic organism, it is inferred that the activated sludge portion of a treatment facility engenders their proliferation.

\subsubsection{Membrane bioreactors/trickling filters}

No reports of Leptospira spp. reductions by membrane bioreactors or trickling filters were identified.

3.1.6.4 Anaerobic digestion and biogas

The absence of oxygen, even in otherwise favorable growth conditions, will inhibit the survivability of leptospires in manure and sludge matrices (Diesch, 1971). It can then be inferred that anaerobic digestion of sludges would be a favorable environment for the eradication of infective leptospires. A study done by McGarry and Stainforth (1978) investigated the effect of biogases on the survivability of Leptospira icterohaemorrhagica, finding that the spirochetes died within 31 hours after introduction of biogas as compared to 300 hours in the control.

\subsection{Disinfection as a Tertiary (or Post Primary) Treatment and Drinking Water}

\subsubsection{Chlorine disinfection}

As a tertiary treatment method for wastewater, chlorine appears to be the most relied upon treatment for the eradication of pathogens, including Leptospira, and is the recommended approach by the EPA (USEPA, 1999). Depending on the chlorine demand of the secondary effluent matrix, the recommended dosage range for tertiary treatment is $5-30 \mathrm{mg} / \mathrm{L}$. These values are corroborated by a 1948 study where all leptospires were killed within one minute at a neutral $\mathrm{pH}$ and chlorine residual of $3.5 \mathrm{mg} / \mathrm{L}$, or within three minutes at a residual of $1 \mathrm{mg} / \mathrm{L}$ (Chang et al., 1948). Unfortunately, specific Ct (concentration x time) values could not be identified.

\subsubsection{UV disinfection and natural processes}

Leptospires are also considered highly susceptible to UV light and Leptospira cultures were killed by direct exposure to sunlight for 1-2 hours in distilled water (Faine et al., 1999). In a study, exposure to UV light $(10 \mathrm{~J} / \mathrm{m} 2)$ resulted in inactivation of most pathogenic Leptospira strains in contrast to non-pathogenic leptospires which were more resistant to the same UV radiation dose; this study also showed that Leptospira is more sensitive to UV radiation than other bacteria such as E. coli (Stamm and Charon, 1988). 


\section{References}

Benbrik, E., Pouliquen, P. and Dômont, A. (2001). Evaluation de la tolérance de la vaccination contre Leptospira icterohaemorrhagiae chez 50 employés de canaux. Archives des Maladies Professionnelles. 62, pp. 35-40.

Adler, B. (2015). Vaccines against leptospirosis. Curr Top Microbiol Immunol.Curr Top Microbiol Immunol. pp. 387:251-272.

Adler, B. (2015). History of leptospirosis and leptospira. Curr Top Microbiol Immunol. Curr Top Microbiol Immunol. 387, pp. 1-9.

Adler, B. and de la Peña-Moctezuma, A. (2010). Leptospira and leptospirosis. Vet MicrobiolVet Microbiol. 140, pp. 287-96.

Agampodi, S.B., Karunarathna, D., Jayathilala, N., Rathnayaka, H., Agampodi, T.C. and Karunanayaka, L. (2014). Outbreak of leptospirosis after white-water rafting: sign of a shift from rural to recreational leptospirosis in Sri Lanka. Epidemiol InfectEpidemiol InfectEpidemiol Infect. 142, pp. 843-6.

Alexander, A.D., Evans, L.B., Baker, M.F., Ellison, D. and Marriapan, M. (1975). Pathogenic Leptospiras Isolated from Malaysian Surface Waters. Appl MicrobiolAppl Microbiol. 29, pp. 30-33.

Ali, M.R.Mohd, Safiee, A.W.Mohamad, Yusof, N.Y., Fauzi, M.H., C. Yean, Y. and Ismail, N. (2018). Isolation of Leptospira kmetyi from residential areas of patients with leptospirosis in Kelantan, Malaysia. J Infect Public HealthJ Infect Public HealthJ Infect Public Health. 2017/12/27 ed.11, pp. 578-580.

Alston, J.M. (1935). Leptospiral Jaundice Among Sewer-workers. The Lancet. 225, pp. 806-809.

Andre-Fontaine, G., Aviat, F. and Thorin, C. (2015). Waterborne Leptospirosis: Survival and Preservation of the Virulence of Pathogenic Leptospira spp. in Fresh Water. Curr MicrobiolCurr Microbiol. 71, pp. 136-142.

Andreoli, E., Radaelli, E., Bertoletti, I., Bianchi, A., Scanziani, E., Tagliabue, S. et al. (2014). Leptospira spp. infection in wild ruminants: a survey in Central Italian Alps. Vet Ital.Vet Ital. 50, pp. 285-291.

Andrews, R.D., Reilly, J.R., Ferris, D.H. and Hanson, L.E. (1965). Leptospiral Agglutinins in Sera from Southern Illinois Herpetofauna. J. Wildl. Dis.J. Wildl. Dis. 1, pp. 55-59.

Athanazio, D.A., Silva, E.F., Santos, C.S., Rocha, G.M., Vannier-Santos, M.A., McBride, A.J. et al. (2008). Rattus norvegicus as a model for persistent renal colonization by pathogenic Leptospira interrogans. Acta Trop.Acta Trop. 105, pp. 176-180.

Avalos-Téllez, R., Carrillo-Casas, E.M., Atilano-López, D., Godínez-Reyes, C.R., Díaz-Aparicio, E., Ramírez-Delgado, D. et al. (2016). Pathogenic Leptospira serovars in free-living sea lions in the gulph of California and along the Baja California coast of Mexico. J Wildl Dis.J Wildl Dis. 52, pp. 199-208.

Aviat, F., Rochereau-Roulet, S., Branger, C., Estavoyer, J.M., Chatrenet, B., Orsonneau, J.L. et al. (2010). Synthetic peptide issued from Hap1/LipL32 for new early serodiagnosis of human leptospirosis. Comp Immunol Microbiol Infect DisComp Immunol Microbiol Infect DisComp Immunol Microbiol Infect Dis. 33, pp. 375-387.

Azali, M.A., C. Yean, Y., Harun, A., Baki, N.N.Aminudd and Ismail, N. (2016). Molecular Characterization of Leptospira spp. in Environmental Samples from North-Eastern Malaysia Revealed a Pathogenic Strain, Leptospira alstonii. J Trop MedJ Trop MedJ Trop Med. 2016/04/30 ed.2016, pp. 2060241.

Azocar-Aedo, L., Monti, G. and Jara, R. (2014). Leptospira spp. in Domestic Cats from Different Environments: Prevalence of Antibodies and Risk Factors Associated with the Seropositivity. Animals (Basel)Animals (Basel). 4, pp. 612-626.

Baker, M.F. and Baker, H.J. (1970). Pathogenic Leptospira in Malaysian surface waters. I. A method of survey for Leptospira in natural waters and soils. Am J Trop Med HygAm J Trop Med HygAm J Trop Med Hyg. 1970/05/01 ed.19, pp. 485-92. 
Barragan, V.A., Mejia, M.E., Travez, A., Zapata, S., Hartskeerl, R.A., Haake, D.A. et al. (2011). Interactions of Leptospira with Environmental Bacteria from Surface Water. Curr MicrobiolCurr MicrobiolCurr Microbiol. 62, pp. 1802-1806.

Barragan, V., Nieto, N., Keim, P. and Pearson, T. (2017). Meta-analysis to estimate the load of Leptospira excreted in urine: beyond rats as important sources of transmission in low-income rural communities. BMC Res NotesBMC Res NotesBMC Res Notes. 2017/01/29 ed.10, pp. 71.

Beigel, B. and Verma, A. (2017). Leptospira: Molecular Detection of Pathogenic Species in Natural Sources. Curr Protoc MicrobiolCurr Protoc MicrobiolCurr Protoc Microbiol. 2017/11/10 ed.47, pp. 12E 6 1-12E 68.

Benacer, D., Woh, P.Y., Zain, S.N.Mohd, Amran, F. and Thong, K.L. (2013). Pathogenic and Saprophytic Leptospira Species in Water and Soils from Selected Urban Sites in Peninsular Malaysia. Microbes EnvironMicrobes EnvironMicrobes Environ. 2013/02/01 ed.28, pp. 135-140.

Bharti, A.R., Nally, J.E., Ricaldi, J.N., Matthias, M.A., Diaz, M.M., Lovett, M.A. et al. (2003). Leptospirosis: a zoonotic disease of global importance. Lancet Infect DisLancet Infect DisLancet Infect Dis. 3, pp. 757-71.

Bogomolni, A.L., Gast, R.J., Ellis, J.C., Dennett, M., Pugliares, K.R., Lentell, B.J. et al. (2008). Victims or vectors: a survey of marine vertebrate zoonoses from coastal waters of the Northwest Atlantic. Dis Aquat OrganDis Aquat OrganDis Aquat Organ. 2008/10/03 ed.81, pp. 13-38.

Bradley, J.A., Daille, L.K., Trivedi, C.B., Bojanowski, C.L., Stamps, B.W., Stevenson, B.S. et al. (2017). Carbonate-rich dendrolitic cones: insights into a modern analog for incipient microbialite formation, Little Hot Creek, Long Valley Caldera, California. NPJ Biofilms MicrobiomesNPJ Biofilms MicrobiomesNPJ Biofilms Microbiomes. 2017/11/28 ed.3, pp. 32.

Brem, S., Radu, O., Bauer, T., Schonberg, A., Reisshauer, K., Waidmann, R. et al. (1995). [Leptospira infected rat population as probable cause of a fatal case of Weil's disease]. Berl Munch Tierarztl WochenschrBerl Munch Tierarztl Wochenschr. 108, pp. 405-7.

Brenner, D.J., Kaufmann, A.F., Sulzer, K.R., Steigerwalt, A.G., Rogers, F.C. and Weyant, R.S. (1999). Further determination of DNA relatedness between serogroups and serovars in the family Leptospiraceae with a proposal for Leptospira alexanderi sp. nov. and four new Leptospira genomospecies. International Journal of Systematic and Evolutionary MicrobiologyInternational Journal of Systematic and Evolutionary Microbiology. 49, Microbiology Society. pp. 839-858.

Bulach, D.M., Zuerner, R.L., Wilson, P., Seemann, T., McGrath, A., Cullen, P.A. et al. (2006). Genome reduction in Leptospira borgpetersenii reflects limited transmission potential. Proc Natl Acad Sci U S A.Proc Natl Acad Sci U S A. 103, pp. 14560-14565.

Cacciapuoti, B., Ciceroni, L., Maffei, C., Di Stanislao, F., Strusi, P., Calegari, L. et al. (1987). A waterborne outbreak of leptospirosis. Am J Epidemiol.Am J Epidemiol. 126, pp. 535-545.

Calderon, A., Rodriguez, V., Mattar, S. and Arrieta, G. (2014). Leptospirosis in pigs, dogs, rodents, humans, and water in an area of the Colombian tropics. Trop Anim Health ProdTrop Anim Health Prod. 2013/11/21 ed.46, pp. 427-432.

Cameron, C.E., Zuerner, R.L., Raverty, S., Colegrove, K.M., Norman, S.A., Lambourn, D.M. et al. (2008). Detection of Pathogenic Leptospira in Pinniped Populations via PCR Identifies a Source of Transmission for Zoonotic Leptospirosis in the Marine Environment. J Clin MicrobiolJ Clin MicrobiolJ Clin Microbiol. 46, pp. 1728-1733.

Cangelosi, G.A. (2009). Prospects for applying virulence factor-activity relationships (VFAR) to emerging waterborne pathogens. J Water HealthJ Water HealthJ Water Health. 7 Suppl 1, pp. S64-74.

Cangelosi, G.A., C Zanzi, M., Weigel, K.M. and Nguyen, T.H. (2018). Personal communication. Department of Environmental and Occupational Health Sciences, University of Washington. Seattle, Washington, USA.

Casanovas-Massana, A., Costa, F., Riediger, I.N., Cunha, M., de Oliveira, D., Mota, D.C. et al. (2018). Spatial and temporal dynamics of pathogenic Leptospira in surface waters from the urban slum environment. Water ResWater Res. 130, pp. 176-184. 
Cerri, D., Nuvoloni, R., Ebani, V., Pedrini, A., Mani, P., Andreani, E. et al. (1996). Leptospira interrogans serovar hardjo in the kidneys and genital tracts of naturally infected sheep. New MicrobiolNew Microbiol. 19, pp. 175-178.

Chaiwattanarungruengpaisan, S., Suwanpakdee, S., Sangkachai, N., Chamsai, T., Taruyanon, K. and Thongdee, M. (2018). Potential pathogenic Leptospira species isolated from waterfall in Thailand. Jpn J Infect DisJpn J Infect DisJpn J Infect Dis. 2017/11/03 ed.71, pp. 65-67.

Chakraborty, A., Miyahara, S., Villanueva, S.Y., Saito, M., Gloriani, N.G. and Yoshida, S.I. (2011). A novel combination of selective agents for isolation of Leptospira species. Microbiol ImmunolMicrobiol ImmunolMicrobiol Immunol. 55, pp. 494-501.

Chang, S.L., Buckingham, M. and Taylor, M.P. (1948). Studies on Leptospira icterohaemorrhagiae; survival in water and sewage; destruction in water by halogen compounds, synthetic detergents, and heat. J Infect DisJ Infect DisJ Infect Dis. 1948/05/01 ed.82, pp. 256-66.

Chaturongkasumrit, Y., Techaruvichit, P., Takahashi, H., Kimura, B. and Keeratipibul, S. (2013). Microbiological evaluation of water during the 2011 flood crisis in Thailand. Sci Total EnvironSci Total EnvironSci Total Environ. 2013/07/23 ed.463-464C, pp. 959-967.

Coghlan, J.D. and Kmety, E. (1987). A new serovar mogdeni of serogroup Tarassovi of Leptospira interrogans isolated from a sewage plant in England. Epidemiol InfectEpidemiol InfectEpidemiol Infect. 1987/10/01 ed.99, pp. 373-7.

Colagross-Schouten, A.M., Mazet, J.A., Gulland, F.M., Miller, M.A. and Hietala, S. (2002). Diagnosis and seroprevalence of leptospirosis in California sea lions from coastal California. J Wildl Dis.J Wildl Dis. 38, pp. 7-17.

Concepcion-Acevedo, J., Patel, A., Luna-Pinto, C., Pena, R.G., Ruiz, R.I.Cuevas, Arbolay, H.R. et al. (2018). Initial Public Health Laboratory Response After Hurricane Maria - Puerto Rico, 2017. MMWR Morb Mortal Wkly Rep. 67, pp. 333-336.

Corwin, A., Ryan, A., Bloys, W., Thomas, R., Deniega, B. and Watts, D. (1990). A waterborne outbreak of leptospirosis among United States military personnel in Okinawa, Japan. Int J Epidemiol. 19, pp. 743-748.

Costa, F., Hagan, J.E., Calcagno, J., Kane, M., Torgerson, P., Martinez-Silveira, M.S. et al. (2015). Global Morbidity and Mortality of Leptospirosis: A Systematic Review. PLoS Negl Trop DisPLoS Negl Trop DisPLoS Negl Trop Dis. 2015/09/18 ed.9, pp. e0003898.

Costa, F., Ribeiro, G.S., Felzemburgh, R.D., Santos, N., Reis, R.B., Santos, A.C. et al. (2014). Influence of household rat infestation on leptospira transmission in the urban slum environment. PLoS Negl Trop DisPLoS Negl Trop DisPLoS Negl Trop Dis. 8, pp. e3338.

Coutinho, M.L., Matsunaga, J., Wang, L.C., de la Peña-Moctezuma, A., Lewis, M.S., Babbitt, J.T. et al. (2014). Kinetics of Leptospira interrogans infection in hamsters after intradermal and subcutaneous challenge. PLoS Negl Trop Dis.PLoS Negl Trop Dis. 8, pp. e3307.

Dadon, Y., Haas, E.J., Kaliner, E., Anis, E., Singer, S.R., Atiya-Nasagi, Y. et al. (2018). Outbreak of human leptospirosis linked to contaminated water bodies in Northern Israel, June to August 2018. Eurosurveillance. 23, pp. 1800486.

da Silva, E.F., Felix, S.R., Cerqueira, G.M., Fagundes, M.Q., Neto, A.C., Grassmann, A.A. et al. (2010). Preliminary Characterization of Mus musculus-Derived Pathogenic Strains of Leptospira borgpetersenii Serogroup Ballum in a Hamster Model. Am J Trop Med HygAm J Trop Med HygAm J Trop Med Hyg. 83, pp. 336-7.

de Faria, M.T., Calderwood, M.S., Athanazio, D.A., McBride, A.J., Hartskeerl, R.A., Pereira, M.M. et al. (2008). Carriage of Leptospira interrogans among domestic rats from an urban setting highly endemic for leptospirosis in Brazil. Acta TropActa Trop. 108, pp. 1-5.

de Freitas, T.P., Keuroghlian, A., Eaton, D.P., de Freitas, E.B., Figueiredo, A., Nakazato, L. et al. (2010). Prevalence of Leptospira interrogans antibodies in free-ranging Tayassu pecari of the Southern Pantanal, Brazil, an ecosystem where wildlife and cattle interact. Trop Anim Health ProdTrop Anim Health Prod. 42, pp. 1695-703. 
Deinema, M.H. (1976). Morphological characteristics of a spirochete present in activated sludge. Can J Microbiol. 22, pp. 1768-1771.

Delafont, V., Bouchon, D., Hechard, Y. and Moulin, L. (2016). Environmental factors shaping cultured free-living amoebae and their associated bacterial community within drinking water network. Water ResWater Res. 2016/05/25 ed.100, pp. 382-92.

De Serres, G., Levesque, B., Higgins, R., Major, M., Laliberte, D., Boulianne, N. et al. (1995). Need for vaccination of sewer workers against leptospirosis and hepatitis A. Occup Environ MedOccup Environ MedOccup Environ Med. 1995/08/01 ed.52, pp. 505-7.

Diesch, S.L. (1971). Survival of leptospires in cattle manure. J Am Vet Med AssocJ Am Vet Med AssocJ Am Vet Med Assoc. 1971/12/01 ed.159, pp. 1513-1517.

Diesch, S.L. and McCulloch, W.F. (1966). Isolation of pathogenic leptospires from waters used for recreation. Public Health RepPublic Health RepPublic Health Rep. 1966/04/01 ed.81, pp. 299-304.

Dietrich, M., Muhldorfer, K., Tortosa, P. and Markotter, W. (2015). Leptospira and Bats: Story of an emerging friendship. PLoS PathogPLoS Pathog. 11, pp. e1005176.

Duncan, C., Krafsur, G., Podell, B., Baeten, L.A., LeVan, I., Charles, B. et al. (2012). Leptospirosis and tularaemia in raccoons (Procyon lotor) of Larimer County,. Zoonoses Public HealthZoonoses Public Health. 59, pp. 29-34.

Easton, A. (1999). Leptospirosis in Philippine floods. BMJBMJ. 1999/07/23 ed.319, pp. 212.

Ellis, G.R., Partington, D.L., Hindmarsh, M. and Barton, M.D. (1994). Seroprevalence to Leptospira interrogans serovar hardjo in merino stud rams in South Australia. Aust Vet JAust Vet J. 71, pp. 203-206.

Ellis, W.A., McParland, P.J., Bryson, D.G. and Cassells, J.A. (1986). Boars as carriers of leptospires of the Australis serogroup on farms with an abortion problem. Vet RecVet Rec. 118, pp. 563.

Ellis, W.A., Songer, J.G., Montgomery, J. and Cassells, J.A. (1986). Prevalence of Leptospira interrogans serovar hardjo in the genital and urinary tracts of non-pregnant cattle. Vet RecVet Rec. 118, pp. 11-3.

Ensuncho-Hoyos, C., Rodriguez-Rodriguez, V., Perez-Doria, A., Vergara, O. and Calderon-Rangel, A. (2017). Epidemiology behavior of leptospirosis in Cienaga de Oro, Cordoba (Colombia). Trop Anim Health ProdTrop Anim Health Prod. 2017/07/01 ed.49, pp. 1345-1351.

Escobedo-Hinojosa, W. and Pardo-Lopez, L. (2017). Analysis of bacterial metagenomes from the Southwestern Gulf of Mexico for pathogens detection. Pathog DisPathog DisPathog Dis. 2017/05/24 ed.75, pp. ftx058.

Evangelista, K.V. and Coburn, J. (2010). Leptospira as an emerging pathogen: a review of its biology, pathogenesis and host immune responses. Future Microbiol.Future Microbiol. 5, pp. 1413-1425.

Faine, S., Adler, B., Bolin, C. and Perolat, P. (1999). Leptospira and Leptospirosis, Second Edition. (.., ed.). MedSci, Melbourne, Vic. Australia. Melbourne, Australia. pp. 272.

Forster, K.M., Hartwig, D.D., Seixas, F.K., Bacelo, K.L., Amaral, M., Hartleben, C.P. et al. (2013). A conserved region of leptospiral immunoglobulin-like A and B proteins as a DNA vaccine elicits a prophylactic immune response against leptospirosis. Clin Vaccine Immunol.Clin Vaccine Immunol. 20, pp. 725-731.

Fraga, T.R., Barbosa, A.S. and Isaac, L. (2011). Leptospirosis: Aspects of Innate Immunity, Immunopathogenesis and Immune Evasion from the Complement System. Scand J Immunol. 73, pp. 408-419.

Fuh, Y.B., Shia, W.Y., Lee, W.M., Shyu, C.L., Wang, C.Y. and Fei, C.Y. (2011). The use of commercial soil nucleic acid extraction kit and nested PCR for detection of Leptospira in farm environment after flooding in Taiwan. Thai Journal of Veterinary MedicineThai Journal of Veterinary Medicine. 41, pp. 493-498. 
Ganoza, C.A., Matthias, M.A., Collins-Richards, D., Brouwer, K.C., Cunningham, C.B., Segura, E.R. et al. (2006). Determining risk for severe leptospirosis by molecular analysis of environmental surface waters for pathogenic Leptospira. PLoS MedPLoS Med. 3, pp. e308.

Ganoza, C.A., Matthias, M.A., Saito, M., Cespedes, M., Gotuzzo, E. and Vinetz, J.M. (2010). Asymptomatic Renal Colonization of Humans in the Peruvian Amazon by Leptospira. PLoS Negl Trop Dis. 4, pp. e612.

Gasca, C.A.Carmona, Ko, A.I., Ahmed, N., Hartskeerl, R. and de la Peña-Moctezuma, A. (2013). Isolation and molecular characterization of Leptospira borgpetersenii serovar Ballum. Tropical and Subtropical Agroecosystems.Tropical and Subtropical Agroecosystems. 16, pp. 143-153.

Gay, N., Soupé-Gilbert, M.E. and Goarant, C. (2014). Though not reservoirs, dogs might transmit Leptospira in New Caledonia. Int J Environ Res Public Health. 11, pp. 4316-4325.

Gaynor, K., Katz, A.R., Park, S.Y., Nakata, M., Clark, T.A. and Effler, P.V. (2007). Leptospirosis on Oahu: an outbreak associated with flooding of a university campus. Am J Trop Med HygAm J Trop Med HygAm J Trop Med Hyg. 76, pp. 882-5.

Gedalanga, P.B. and Olson, B.H. (2009). Development of a quantitative PCR method to differentiate between viable and nonviable bacteria in environmental water samples. Appl Microbiol BiotechnolAppl Microbiol BiotechnolAppl Microbiol Biotechnol. 82, pp. 587-596.

Gelling, M., Zochowski, W., Macdonald, D.W., Johnson, A., Palmer, M. and Mathews, F. (2015). Leptospirosis acquisition following the reintroduction of wildlife. Vet RecVet Rec. 2015/10/21 ed.177, pp. 440.

Gillespie, R.W.H. and Ryno, J. (1963). Epidemiology of Leptospirosis. American Journal of Public Health and the Nations HealthAmerican Journal of Public Health and the Nations Health. 53, pp. 950-955.

Goldstein, S.F. and Charon, N.W. (1988). Motility of the spirochete Leptospira. Cell Motil CytoskeletCell Motil Cytoskelet. 9, pp. 101-110.

Gomes, C.K., Guedes, M., Potula, H.H., Dellagostin, O.A. and Gomes-Solecki, M. (2018). Sex matters: male hamsters are more susceptible to lethal infection with lower doses of pathogenic Leptospira. Infect Immun. 86, pp. e00369-18.

Guernier, V., Allan, K.J. and Goarant, C. (2018). Advances and challenges in barcoding pathogenic and environmental Leptospira. ParasitologyParasitology. 145, pp. 595-607.

Höglund, C., Stenström, T.A. and Ashbolt, N. (2002). Microbial risk assessment of source-separated urine used in agriculture. Waste Management and Research. 20, pp. 150-161.

Haake, D.A. and Levett, P.N. (2015). Leptospirosis in humans. Curr Top Microbiol ImmunolCurr Top Microbiol ImmunolCurr Top Microbiol Immunol. 2014/11/13 ed.387, pp. 65-97.

Halliwell, R.E., Brim, T.A., Hines, M.T., Wolf, D. and White, F.H. (1985). Studies on equine recurrent uveitis. II: The role of infection with Leptospira interrogans serovar pomona. Curr Eye ResCurr Eye ResCurr Eye Res. 4, pp. 1033-40.

Hartmann, K., Egberink, H., Pennisi, M.G., Lloret, A., Addie, D., Belak, S. et al. (2013). Leptospira Species Infection in Cats: ABCD guidelines on prevention and management. J Feline Med SurgJ Feline Med SurgJ Feline Med Surg. 2013/07/03 ed.15, pp. 576-81.

Henry, R.A. and Johnson, R.C. (1978). Distribution of the genus Leptospira in soil and water. Appl Environ MicrobiolAppl Environ MicrobiolAppl Environ Microbiol. 35, pp. 492-9.

Hickey, C.W., Quinn, J.M. and Davies-Colley, R.J. (1989). Effluent characteristics of dairy shed oxidation ponds and their potential impacts on rivers. New Zealand journal of marine and freshwater research. 23, pp. 569-584.

Holt, J., Davis, S. and Leirs, H. (2006). A model of Leptospirosis infection in an African rodent to determine risk to humans: seasonal fluctuations and the impact of rodent control. Acta Trop.Acta Trop. 99, pp. 218-225. 
Huang, K., Zhang, X.X., Shi, P., Wu, B. and Ren, H. (2014). A comprehensive insight into bacterial virulence in drinking water using 454 pyrosequencing and Illumina high-throughput sequencing. Ecotoxicol Environ SafEcotoxicol Environ SafEcotoxicol Environ Saf. 2014/08/19 ed.109, pp. 15-21.

Ido, Y., Hoki, R., Ito, H. and Wani, H. (1916). The prophylaxis of Weil's disease (Spirochaetosis Icterohaemorrhagica). J Exp MedJ Exp MedJ Exp Med. 1916/11/01 ed.24, pp. 471-83.

Ismail, S., Wahab, N.Zarina Abd, Badya, N., Rahman, N.Iza A., Yeo, C.Chieng, Latif, A.Zubaidi A. et al. (2014). A study on the presence of pathogenic Leptospira spp. in environmental water samples obtained from selected recreational areas in Terengganu, Malaysia. Research Journal of Pharmacy and TechnologyResearch Journal of Pharmacy and Technology. 7, A\&amp;V Publications. pp. 1153.

Ivanova, S., Herbreteau, V., Blasdell, K., Chaval, Y., Buchy, P., Guillard, B. et al. (2012). Leptospira and Rodents in Cambodia: Environmental Determinants of Infection. Am J Trop Med HygAm J Trop Med HygAm J Trop Med Hyg. 2012/06/06 ed.86, pp. 1032-1038.

Jackson, L.A., Kaufmann, A.F., Adams, W.G., Phelps, M.B., Andreasen, C., Langkop, C.W. et al. (1993). Outbreak of leptospirosis associated with swimming. Pediatr Infect Dis JPediatr Infect Dis JPediatr Infect Dis J. 1993/01/01 ed.12, pp. 48-54.

Johnson, R.C. and Rogers, P. (1964). 5-Fluorouracil as a Selective Agent for Growth of Leptospirae. J BacteriolJ Bacteriol. 87, pp. 422-6.

Jones, P.W., Rennison, L.M., Matthews, P.R., Collins, P. and Brown, A. (1981). The occurrence and significance to animal health of Leptospira, Mycobacterium, Escherichia coli, Brucella abortus and Bacillus anthracis in sewage and sewage sludges. J Hyg (Lond)J Hyg (Lond)J Hyg (Lond). 1981/02/01 ed.86, pp. 129-37.

Jr, R.P.Crawfor, Braun, J.L., McCulloch, W.F. and Diesch, S.L. (1969). Characterization of leptospires isolated from surface waters in Iowa. Wildlife diseaseWildlife disease. 5, pp. 157-165.

Karaseva, E.V., G. Yu, C. and Sakhartseva, T.F. (1977). Results of the investigation of soil for contamination with pathogenic leptospires. Folia Parasitol (Praha)Folia Parasitol (Praha)Folia Parasitol (Praha). 1977/01/01 ed.24, pp. 301-4.

Katz, A.R., Ansdell, V.E., Effler, P.V., Middleton, C.R. and Sasaki, D.M. (2002). Leptospirosis in Hawaii, 1974-1998: epidemiologic analysis of 353 laboratory-confirmed cases. Am J Trop Med HygAm J Trop Med HygAm J Trop Med Hyg. 66, pp. 61-70.

Kim, J.S. (1987). Leptospirosis: a newly identified disease in Korea. Asia Pac J Public HealthAsia Pac J Public Health. 1, pp. 61-8.

Ko, A.I., Goarant, C. and Picardeau, M. (2009). Leptospira: the dawn of the molecular genetics era for an emerging zoonotic pathogen. Nature Rev Microbiol.Nature Rev Microbiol. 7, pp. 736-747.

Koizumi, N., Muto, M., Tanikawa, T., Mizutani, H., Sohmura, Y., Hayashi, E. et al. (2009). Human leptospirosis cases and the prevalence of rats harbouring Leptospira interrogans in urban areas of Tokyo, Japan. J Med MicrobiolJ Med Microbiol. 58, pp. 1227-1230.

K. Kumar, V., Lall, C., R. Raj, V., Vedhagiri, K., Sunish, I.P. and Vijayachari, P. (2016). In vitro antimicrobial susceptibility of pathogenic Leptospira biofilm. Microb Drug Resist.Microb Drug Resist. [Epub ahead of print] PubMed PMID: 26978023.,

K. Kumar, V., Lall, C., R. Raj, V., Vedhagiri, K. and Vijayachari, P. (2016). Molecular detection of pathogenic leptospiral protein encoding gene (lipL32) in environmental aquatic biofilms. Lett Appl Microbiol.Lett Appl Microbiol. 62, pp. 311-315.

K. Kumar, V., Lall, C., R. Raj, V., Vedhagiri, K. and Vijayachari, P. (2015). Co-existence and survival of pathogenic leptospires by formation of biofilm with Azospirillum. FEMS Microbiol EcolFEMS Microbiol EcolFEMS Microbiol Ecol. 2015/05/13 ed.91, pp. pii:fiv051. 
Kurilung, A., Chanchaithong, P., Lugsomya, K., Niyomtham, W., Wuthiekanun, V. and Prapasarakul, N. (2017). Molecular detection and isolation of pathogenic Leptospira from asymptomatic humans, domestic animals and water sources in Nan province, a rural area of Thailand. Res Vet SciRes Vet SciRes Vet Sci. 2017/04/07 ed.115, pp. 146-154.

Lall, C., Kumar, K.V., Raj, R.V., Vedhagiri, K. and Vijayachari, P. (2016). Prevalence and Diversity of Leptospires in Different Ecological Niches of Urban and Rural Areas of South Andaman Island. Microbes EnvironMicrobes EnvironMicrobes Environ. 2016/03/05 ed.31, pp. 79-82.

Lau, C., Smythe, L. and Weinstein, P. (2010). Leptospirosis: an emerging disease in travellers. Travel Med Infect DisTravel Med Infect DisTravel Med Infect Dis. 8, pp. 33-9.

M. Lavinsky, O., Said, R.A., Strenzel, G.M. and Langoni, H. (2012). Seroprevalence of anti-Leptospira spp. antibodies in dogs in Bahia, Brazil. Prev Vet MedPrev Vet Med. 106, pp. 79-84.

Levett, P.N. (2001). Leptospirosis. Clin Microbiol RevClin Microbiol Rev. 14, pp. 296-326.

Lilenbaum, W., Varges, R., Ristow, P., Cortez, A., Souza, S.O., Richtzenhain, L.J. et al. (2009). Identification of Leptospira spp. carriers among seroreactive goats and sheep by polymerase chain reaction. Res Vet Sci.Res Vet Sci. 87, pp. 16-19.

S. Loffler, G., Rago, V., Martinez, M., Uhart, M., Florin-Christensen, M., Romero, G. et al. (2015). Isolation of a Seawater Tolerant Leptospira spp. from a Southern Right Whale (Eubalaena australis). PLoS OnePLoS ONEPLoS ONE. 2015/12/30 ed.10, pp. e0144974.

Luchini, D., Meacci, F., Oggioni, M.R., Morabito, G., D'Amato, V., Gabbrielli, M. et al. (2008). Molecular detection of Leptospira interrogans in human tissues and environmental samples in a lethal case of leptospirosis. Int J Legal MedInt J Legal MedInt J Legal Med. 122, pp. 229-33.

Malalana, F., Stylianides, A. and McGowan, C. (2015). Equine recurrent uveitis: Human and equine perspectives. Vet J.Vet J. 206, pp. 22-29.

Mason, M.R., Encina, C., Sreevatsan, S. and Muñoz-Zanzi, C. (2016). Distribution and Diversity of Pathogenic Leptospira Species in Peri-domestic Surface Waters from South Central Chile. PLoS Negl Trop DisPLoS Negl Trop DisPLoS Negl Trop Dis. 2016/08/17 ed.10, pp. e0004895.

Massenet, D., Yvon, J.F., Couteaux, C. and Goarant, C. (2015). An unprecedented high incidence of leptospirosis in Futuna, South Pacific, 2004 - 2014, evidenced by retrospective analysis of surveillance data. PLoS OnePLoS ONE. 10, pp. e0142063.

Masuzawa, T., Sakakibara, K., Saito, M., Hidaka, Y., Villanueva, S., Yanagihara, Y. et al. (2018). Characterization of Leptospira species isolated from soil collected in Japan. Microbiol ImmunolMicrobiol ImmunolMicrobiol Immunol. 2017/11/07 ed.62, pp. 55-59.

Matono, T., Kutsuna, S., Koizumi, N., Fujiya, Y., Takeshita, N., Hayakawa, K. et al. (2015). Imported Flood-Related Leptospirosis From Palau: Awareness of Risk Factors Leads to Early Treatment. J Travel MedJ Travel MedJ Travel Med. 2015/10/28 ed.22, pp. 422-4.

McGarry, M.G. and Stainforth, J. (1978). Compost, fertilizer, and biogas production from human and farm wastes in the People's Republic of China. IDRC, Ottawa, ON, CA.

Mgode, G.F., Machang'u, R.S., Mhamphi, G.G., Katakweba, A., Mulungu, L.S., Durnez, L. et al. (2015). Leptospira Serovars for Diagnosis of Leptospirosis in Humans and Animals in Africa: Common Leptospira Isolates and Reservoir Hosts. PLoS Negl Trop DisPLoS Negl Trop DisPLoS Negl Trop Dis. 2015/12/02 ed.9, pp. e0004251.

Minette, H.P. (1983). Leptospirosis in poikilothermic vertebrates. A review. Int J ZoonosesInt J ZoonosesInt J Zoonoses. 10, pp. 111-21.

Moinet, M., Fournier-Chambrillon, C., Andre-Fontaine, G., Aulagnier, S., Mesplede, A., Blanchard, B. et al. (2010). Leptospirosis in free-ranging endangered European mink (Mustela lutreola) and other small carnivores 
(Mustelidae, Viverridae) from southwestern France. J Wildl DisJ Wildl DisJ Wildl Dis. 46, pp. 1141-51.

Morgan, J., Bornstein, S.L., Karpati, A.M., Bruce, M., Bolin, C.A., Austin, C.C. et al. (2002). Outbreak of leptospirosis among triathlon participants and community residents in Springfield, Illinois, 1998. Clin Infect DisClin Infect DisClin Infect Dis. 34, pp. 1593-9.

Morrison, W.I. and Wright, N.G. (1976). Canine leptospirosis: an immunopathological study of interstitial nephritis due to Leptospira canicola. J PatholJ PatholJ Pathol. 120, pp. 83-9.

Muñoz-Zanzi, C., Mason, M.R., Encina, C., Astroza, A. and Romero, A. (2014). Leptospira Contamination in Household and Environmental Water in Rural Communities in Southern Chile. Int J Environ Res Public HealthInt J Environ Res Public HealthInt J Environ Res Public Health. 2014/06/28 ed.11, pp. 6666-6680.

Nardone, A., Capek, I., Baranton, G., Campese, C., Postic, D., Vaillant, V. et al. (2004). Risk factors for leptospirosis in metropolitan France: results of a national case-control study, 1999-2000. Clin Infect Dis. 39, pp. 751-3.

Neiffer, D.L., Klein, E.C. and Wallace-Switalski, C. (2001). Leptospira infection in two black rhinoceroses (Diceros bicornis michaeli). J Zoo Wildl Med.J Zoo Wildl Med. 32, pp. 476-486.

Noguchi, H. (1918). The Survival of Leptospira (Spirochaeta) Icterohaemorrhagiae in Nature; Observations Concerning Microchemical Reactions and Intermediary Hosts. J Exp MedJ Exp MedJ Exp Med. 1918/05/01 ed.27, pp. 609-25.

Pérez, J. and Goarant, C. (2010). Rapid Leptospira identification by direct sequencing of the diagnostic PCR products in New Caledonia. BMC MicrobiolBMC Microbiol. 10, pp. 325.

Parker, J. and Walker, M. (2011). Survival of a pathogenic Leptospira serovar in response to combined in vitro pH and temperature stresses. Vet MicrobiolVet Microbiol. 152, pp. 146-150.

Park, S.Y., Effler, P.V., Nakata, M., Sasaki, D., Katz, A.R., Clark, T.A. et al. (2006). Brief report: Leptospirosis after flooding of a university campus--Hawaii, 2004. MMWR Morb Mortal Wkly RepMMWR Morb Mortal Wkly RepMMWR Morb Mortal Wkly Rep. 55, pp. 125-7.

Perolat, P., Chappel, R.J., Adler, B., Baranton, G., Bulach, D.M., Billinghurst, M.L. et al. (1998). Leptospira fainei sp. nov., isolated from pigs in Australia. Int J Syst BacteriolInt J Syst Bacteriol. 48, pp. 851-858.

Picardeau, M. (2013). Diagnosis and epidemiology of leptospirosis. Med Malad Infect.Med Malad Infect. 43, pp. 1-9.

Picardeau, M., Brenot, A. and I. Girons, S. (2001). First evidence for gene replacement in Leptospira spp. Inactivation of L. biflexa flaB results in non-motile mutants deficient in endoflagella. Mol Microbiol. 40, pp. 189-199.

Picardeau, M., Bulach, D.M., Bouchier, C., Zuerner, R.L., Zidane, N., Wilson, P.J. et al. (2008). Genome Sequence of the Saprophyte Leptospira biflexa Provides Insights into the Evolution of Leptospira and the Pathogenesis of Leptospirosis. PLoS ONEPLoS ONEPLoS ONE. 3, pp. e1607.

Pinna, M.H., Martins, G., Pinheiro, A.C., Almeida, D.S., Oriá, A.P. and Lilenbaum, W. (2012). Detection of anti-Leptospira antibodies in captive nonhuman primates from Salvador, Brazil. Am J Primatol. Am J Primatol. 74, pp. 8-11.

Prager, K.C., Greig, D.J., Alt, D.P., Galloway, R.L., Hornsby, R.L., Palmer, L.J. et al. (2013). Asymptomatic and chronic carriage of Leptospira interrogans serovar Pomona in California sea lions (Zalophus californianus). Vet Microbiol.Vet Microbiol. 164, pp. 177-183.

Pui, C.F., Bilung, L.M., Apun, K. and Su'ut, L. (2017). Diversity of Leptospira spp. in Rats and Environment from Urban Areas of Sarawak, Malaysia. J Trop MedJ Trop MedJ Trop Med. 2017/03/30 ed.17, pp. 3760674.

Pui, C.Fung, Bilung, L.Maurice, Su'ut, L., Chong, Y.Ling and Apun, K. (2017). Detection of Leptospira spp. in Selected National Service Training Centres and Paddy Fields of Sarawak, Malaysia using Polymerase Chain Reaction Technique. Pertanika Journal of Tropical Agricultural SciencePertanika Journal of Tropical Agricultural Science. 40, 
Ramadass, P., Jarvis, B.D.W., Corner, R.J., Penny, D. and Marshall, R.B. (1992). Genetic characterization of pathogenic Leptospira species by DNA hybridization. International Journal of Systematic and Evolutionary MicrobiologyInternational Journal of Systematic and Evolutionary Microbiology. 42, Microbiology Society. pp. 215-219.

Rawlins, J., Portanova, A., Zuckerman, I., Loftis, A., Ceccato, P., Willingham, A.L. et al. (2014). Molecular detection of leptospiral DNA in environmental water on st. Kitts. Int J Environ Res Public HealthInt J Environ Res Public HealthInt J Environ Res Public Health. 2014/08/12 ed.11, pp. 7953-60.

Ridzlan, F.R., Bahaman, A.R., Khairani-Bejo, S. and Mutalib, A.R. (2010). Detection of pathogenic Leptospira from selected environment in Kelantan and Terengganu, Malaysia. Trop BiomedTrop BiomedTrop Biomed. 27, pp. 632-8.

Riediger, I.N., Hoffmaster, A.R., Casanovas-Massana, A., Biondo, A.W., Ko, A.I. and Stoddard, R.A. (2016). An Optimized Method for Quantification of Pathogenic Leptospira in Environmental Water Samples. PLoS OnePLoS ONEPLoS ONE. 2016/08/04 ed.11, pp. e0160523.

Ris, D.R. and Hamel, K.L. (1979). The isolation of leptospires from an air-conditioning plant. N Z Med J. 1979 Sep 12;90(643):212.

Ristow, P., Bourhy, P., Kerneis, S., Schmitt, C., Prevost, M.C., Lilenbaum, W. et al. (2008). Biofilm formation by saprophytic and pathogenic leptospires. MicrobiologyMicrobiologyMicrobiology. 154, pp. 1309-17.

P. Rossa, D., Tantrakarnapa, K., Sutdan, D., Kasetsinsombat, K., Cosson, J.F., Supputamongkol, Y. et al. (2016). Environmental factors and public health policy associated with human and rodent infection by leptospirosis: a land cover-based study in Nan province, Thailand. Epidemiol InfectEpidemiol InfectEpidemiol Infect. 2015/11/27 ed.144, pp. 1550-1562.

Ryu, E. and Liu, C.K. (1966). The viability of leptospires in the summer paddy water. Jpn J MicrobiolJpn J MicrobiolJpn J Microbiol. 1966/04/01 ed.10, pp. 51-7.

Ryu, S., Lau, C.L. and Chun, B.C. (2017). The impact of Livestock Manure Control Policy on human leptospirosis in Republic of Korea using interrupted time series analysis. Epidemiol InfectEpidemiol InfectEpidemiol Infect. 2017/02/22 ed.145, pp. 1320-1325.

Saito, M., Miyahara, S., Villanueva, S.Y., Aramaki, N., Ikejiri, M., Kobayashi, Y. et al. (2014). PCR and culture identification of pathogenic Leptospira from coastal soil in Leyte, Philippines after a storm surge during Super Typhoon Haiyan (Yolanda). Appl Environ MicrobiolAppl Environ MicrobiolAppl Environ Microbiol. 2014/08/31 ed.80, pp. 6926-6932.

Saito, M., Villanueva, S.Y., Chakraborty, A., Miyahara, S., Segawa, T., Asoh, T. et al. (2013). Comparative analysis of Leptospira strains isolated from environmental soil and water in the Philippines and Japan. Appl Environ Microbiol.Appl Environ Microbiol. 79, pp. 601-609.

Saito, M., Villanueva, S.Y., Masuzawa, T., Haraguchi, Y., Ita, S., Miyahara, S. et al. (2015). The usefulness of semi-solid medium in the isolation of highly virulent Leptospira strains from wild rats in an urban area of Fukuoka, Japan. Microbiol ImmunolMicrobiol ImmunolMicrobiol Immunol. 59, pp. 322-30.

Sanchez, C. (2008). Personal communication. Department of Microbiology and Immunology, School of Veterinary Medicine and Zootechnics, Universidad Nacional Autonoma de Mexico. Mexico City, Distrito Federal, Mexico.

Sapian, M., Khair, M.T., How, S.H., Rajalingam, R., Sahhir, K., Norazah, A. et al. (2012). Outbreak of melioidosis and leptospirosis co-infection following a rescue operation. Med J MalaysiaMed J MalaysiaMed J Malaysia. 2012/10/23 ed.67, pp. 293-7.

Schmid, G.P., Steere, A.C., Kornblatt, A.N., Kaufmann, A.F., Moss, C.W., Johnson, R.C. et al. (1986). Newly recognized Leptospira species ("Leptospira inadai" serovar lyme) isolated from human skin. J Clin MicrobiolJ Clin MicrobiolJ Clin Microbiol. 24, pp. 484-6.

Schuller, S., Arent, Z.J., Gilmore, C. and Nally, J. (2015). Prevalence of antileptospiral serum antibodies in dogs in Ireland. Vet Rec. Vet Rec. 177, pp. 126.

Scialfa, E., Brihuega, B., Venzano, A., Morris, W.E., Bolpe, J. and Schettino, M. (2013). First isolation of Leptospira 
interrogans from Lycalopex griseus (South American gray fox) in Argentina shows new MLVA genotype. J Wildl Dis. 49, pp. 168-172.

Sejvar, J., Bancroft, E., Winthrop, K., Bettinger, J., Bajani, M., Bragg, S. et al. (2003). Leptospirosis in "Eco-Challenge" athletes, Malaysian Borneo, 2000. Emerg Infect DisEmerg Infect DisEmerg Infect Dis. 9, pp. 702-7.

Smith, C.E.G. and Turner, L.H. (1961). The effect of pH on the survival of leptospires in water. Bulletin WHOBulletin WHO. 24, pp. 35-43.

Smith, D.J. and Self, H.R. (1955). Observations on the survival of Leptospira australis A in soil and water. J Hyg (Lond)J Hyg (Lond)J Hyg (Lond). 53, pp. 436-44.

Smith, J.K., Young, M.M., Wilson, K.L. and Craig, S.B. (2013). Leptospirosis following a major flood in Central Queensland, Australia. Epidemiol InfectEpidemiol InfectEpidemiol Infect. 2012/05/26 ed.141, pp. 585-590.

Soupé-Gilbert, M.E., Bierque, E., Geroult, S., Teurlai, M. and Goarant, C. (2017). Continuous excretion of Leptospira borgpetersenii Ballum in mice assessed by viability-quantitative PCR. Am J Trop Med HygAm J Trop Med Hyg. 97, pp. 1088-1093.

Stalheim, O.H. (1968). Vaccination of hamsters, swine, and cattle with viable, avirulent Leptospira pomona. Am J Vet Res.Am J Vet Res. 29, pp. 1463-1468.

Stamm, L.V. and Charon, N.W. (1988). Sensitivity of pathogenic and free-living Leptospira spp. to UV radiation and mitomycin C. Appl Environ Microbi. 54, pp. 728-33.

Stern, E.J., Galloway, R., Shadomy, S.V., Wannemuehler, K., Atrubin, D., Blackmore, C. et al. (2010). Outbreak of leptospirosis among Adventure Race participants in Florida, 2005. Clinical Infectious DiseasesClinical Infectious Diseases. 50, The University of Chicago Press. pp. 843-849.

Strand, T.M., Lohmus, M., T. Vinnersten, P., Rasback, T., Sundstrom, K., Bergstrom, T. et al. (2015). Highly Pathogenic Leptospira Found in Urban Brown Rats (Rattus norvegicus) in the Largest Cities of Sweden. Vector Borne Zoonotic DisVector Borne Zoonotic DisVector Borne Zoonotic Dis. 2015/11/19 ed.15, pp. 779-781.

Subharat, S., Wilson, P.R., Heuer, C. and Collins-Emerson, J.M. (2012). Growth response and shedding of Leptospira spp. in urine following vaccination for leptospirosis in young farmed deer. New Zealand veterinary journalNew Zealand veterinary journal. 60, Taylor \&amp; Francis. pp. 14-20.

Tansuphasiri, U., Thipsuk, C., Phulsuksombati, D. and Chanyasanha, C. (2006). Duplex PCR-hybridization based detection of pathogenic Leptospira in environmental water samples obtained from endemic areas in northeast region of Thailand. Southeast Asian J Trop Med Public HealthSoutheast Asian J Trop Med Public HealthSoutheast Asian J Trop Med Public Health. 37, pp. 729-41.

Thaipadungpanit, J., Wuthiekanun, V., Chantratita, N., Yimsamran, S., Amornchai, P., Boonsilp, S. et al. (2013). Leptospira Species in Floodwater during the 2011 Floods in the Bangkok Metropolitan Region, Thailand. Am J Trop Med HygAm J Trop Med HygAm J Trop Med Hyg. 2013/09/05 ed.89, pp. 794-796.

Thibeaux, R., Geroult, S., Benezech, C., Chabaud, S., Soupé-Gilbert, M.E., Girault, D. et al. (2017). Seeking the environmental source of Leptospirosis reveals durable bacterial viability in river soils. PLoS Negl Trop Dis. 11,.

Thibeaux, R., Girault, D., Bierque, E., Soupé-Gilbert, M.E., Rettinger, A., Douyere, A. et al. (2018). Biodiversity of environmental Leptospira: improving identification and revisiting the diagnosis. Front. Microbiol.Front. Microbiol. 9, pp. 816.

Thibeaux, R., Iraola, G., Ferrés, I., Bierque, E., Girault, D., Soupé-Gilbert, M.E. et al. (2018). Deciphering the unexplored Leptospira diversity from soils uncovers genomic evolution to virulence. Microbial GenomicsMicrobial Genomics. 4, pp. 000144.

Thiermann, A.B. (1981). The Norway rat as a selective chronic carrier of Leptospira icterohaemorrhagiae. J Wildl DisJ Wildl 
DisJ Wildl Dis. 17, pp. 39-43.

Thornley, C.N., Baker, M.G., Weinstein, P. and Maas, E.W. (2002). Changing epidemiology of human leptospirosis in New Zealand. Epidemiol Infect. 128, pp. 29-36.

Trevejo, R.T., Rigau-Perez, J.G., Ashford, D.A., McClure, E.M., Jarquin-Gonzalez, C., Amador, J.J. et al. (1998). Epidemic leptospirosis associated with pulmonary hemorrhage-Nicaragua, 1995. J Infect DisJ Infect DisJ Infect Dis. 1998/10/21 ed.178, pp. 1457-63.

Trueba, G., Zapata, S., Madrid, K., Cullen, P. and Haake, D. (2004). Cell aggregation: a mechanism of pathogenic Leptospira to survive in fresh water. Int Microbiolint Microbiol. 7, pp. 35-40.

USEPA (1999). Wastewater technology fact sheet: chlorine disinfection. United States Environmental Protection Agency, Office of Water.

Vein, J., Perrin, A., Berny, P.J., Benoit, E., Leblond, A. and Kodjo, A. (2012). Adaptation of a real-time PCR method for the detection and quantification of pathogenic leptospires in environmental water. Can J MicrobiolCan J MicrobiolCan J Microbiol. 2012/06/16 ed.58, pp. 828-35.

Verma, A., Stevenson, B. and Adler, B. (2013). Leptospirosis in horses. Vet MicrobiolVet Microbiol. 167, pp. 61-66.

Verma, R., Khanna, P. and Chawla, S. (2013). Whole-cell inactivated leptospirosis vaccine: future prospects. Hum Vaccin Immunother.Hum Vaccin Immunother. 9, pp. 763-765.

Viau, E.J., Goodwin, K.D., Yamahara, K.M., Layton, B.A., Sassoubre, L.M., Burns, S.L. et al. (2011). Bacterial pathogens in Hawaiian coastal streams--associations with fecal indicators, land cover, and water quality. Water ResWater Res. 2011/04/16 ed.45, pp. 3279-90.

Villanueva, S.Y., Saito, M., Baterna, R.A., Estrada, C.A., Rivera, A.K., Dato, M.C. et al. (2014). Leptospira-rat-human relationship in Luzon, Philippines. Microbes InfectMicrobes InfectMicrobes Infect. 16, pp. 902-10.

Vital-Brazil, J.M., Balassiano, I.T., Oliveira, F.S., Costa, A.D., Hillen, L. and Pereira, M.M. (2010). Multiplex PCR-based detection of Leptospira in environmental water samples obtained from a slum settlement. Mem Inst Oswaldo CruzMem Inst Oswaldo CruzMem Inst Oswaldo Cruz. 105, pp. 353-5.

Watanabe, T., Teske, S.S. and Haas, C.N. (2014). Classic dose-response and time postinoculation models for leptospira. Risk AnalRisk AnalRisk Anal. 34, pp. 465-84.

Weinberger, D., Baroux, N., Grangeon, J.-.P., Ko, A.I. and Goarant, C. (2014). El Niño Southern Oscillation and leptospirosis outbreaks in New Caledonia. PLoS Negl Trop Dis. 8, pp. e2798.

WHO (2006). Guidelines for the safe use of wastewater, excreta and greywater. Policy and Regulatory Aspects. 2, Wastewater use in agriculture, World Health Organization (WHO). Geneva, Switzerland.

WHO (1999). WHO recommended standards and strategies for surveillance prevention and control of communicable diseases: Leptospirosis. WHO recommended standards and strategies for surveillance prevention and control of communicable diseases. WHO/CDS/CSR/ISR/99.2, World Health Organization, W.H.O.

Wojcik-Fatla, A., Zajac, V., Wasinski, B., Sroka, J., Cisak, E., Sawczyn, A. et al. (2014). Occurrence of Leptospira DNA in water and soil samples collected in eastern Poland. Ann Agric Environ MedAnn Agric Environ MedAnn Agric Environ Med. 2014/12/23 ed.21, pp. 730-2.

Wollanke, B., Rohrbach, B.W. and Gerhards, H. (2001). Serum and vitreous humor antibody titers in and isolation of Leptospira interrogans from horses with recurrent uveitis. J Am Vet Med AssocJ Am Vet Med AssocJ Am Vet Med Assoc. 219 , pp. 795-800.

Wuthiekanun, V., Amornchai, P., Paris, D.H., Langla, S., Thaipadunpanit, J., Chierakul, W. et al. (2013). Rapid isolation and susceptibility testing of Leptospira spp. using a new solid medium, LVW agar. Antimicrob Agents ChemotherAntimicrob 
Agents ChemotherAntimicrob Agents Chemother. 57, pp. 297-302.

Wynwood, S.J., Craig, S.B., Graham, G.C., Blair, B.R., Burns, M.A., Weier, S.L. et al. (2014). The emergence of Leptospira borgpetersenii serovar Arborea as the dominant infecting serovar following the summer of natural disasters in Queensland, Australia 2011. Trop BiomedTrop BiomedTrop Biomed. 2014/08/20 ed.31, pp. 281-5.

Yasuda, P.H., Steigerwalt, A.G., Sulzer, K.R., Kaufmann, A.F., Rogers, F. and Brenner, D.J. (1987). Deoxyribonucleic acid relatedness between serogroups and serovars in the family Leptospiraceae with proposals for seven new Leptospira species. International Journal of Systematic and Evolutionary MicrobiologyInternational Journal of Systematic and Evolutionary Microbiology. 37, Microbiology Society. pp. 407-415.

Zamora, J.D., Enrique, K.F., Boué, R.G., Torres, F.H., Airado, J.L. and Hernández, D.R. (2005). [Scale-up of the fermentation of Leptospira interrogans canicola canicola for the production of vax-SPIRAL vaccine]. Rev Cubana Med Trop.Rev Cubana Med Trop. 57, pp. 71-72.

Zhang, Y., Kitajima, M., Whittle, A.J. and Liu, W.-.T. (2017). Benefits of Genomic Insights and CRISPR-Cas Signatures to Monitor Potential Pathogens across Drinking Water Production and Distribution Systems. Front MicrobiolFront Microbiol. 8, pp. 2036. 